\title{
Alpha-synuclein in the nucleus accumbens induces changes in cocaine behaviour in rats
}

\author{
Frederic Boyer and Jean-Luc Dreyer \\ Institute of Biochemistry, University of Fribourg, Rue du Musée 5, CH-1700 Fribourg, Switzerland
}

Keywords: addiction, drugs of abuse, in vivo gene transfer, lentivirus, plasticity, siRNA

\begin{abstract}
The mesolimbic dopaminergic system is widely recognized to be critical to the neurobiology of cocaine reward and addiction. The neuronal protein, $\alpha$-synuclein, is an important regulator in dopaminergic transmission. It interacts with the dopamine transporter, and regulates dopaminergic content, neurotransmission and synaptic strength of dopaminergic neurons. Alpha-synuclein levels are elevated in midbrain dopamine neurons of chronic cocaine abusers, and its expression is increased in psychostimulant-treated animals [M.S. Brenz-Verca et al. (2003) J. Neurosci., 18, 1923-1938]. This suggests a role for $\alpha$-synuclein in psychostimulantinduced behavioural effects. To investigate this hypothesis, we tested the effect of stimulation and silencing of $\alpha$-synuclein expression in the nucleus accumbens (NAcc) on two cocaine-induced behavioural effects in the rat. For this purpose, animals were administered with lentiviruses driving $\alpha$-synuclein overexpression under the control of a doxycycline regulatable promoter and/or with three lentiviruses expressing target-specific siRNAs, aimed at silencing $\alpha$-synuclein mRNA expression. Animals were then tested for cocaine-induced locomotion (15 mg/kg i.p.) or cocaine-induced intravenous self-administration (SA; $0.7 \mathrm{mg} / \mathrm{kg}, 1 \mathrm{~h} / \mathrm{day}$ ). Overexpression of $\alpha$-synuclein in the NAcc induced a $45 \%$ increase in locomotor activity and a 1.9-fold increase of cocaine SA, which could be abolished when the same animal was fed doxycycline. Furthermore, local inhibition of $\alpha$-synuclein in the NAcc resulted in significant hypolocomotion activity and a decrease in SA. Our results demonstrate that $\alpha$-synuclein is able to modulate cocaine-induced behavioural effects. This suggests that targeting $\alpha$-synuclein function could provide new therapeutic strategies to treat cocaine abuse, for which there is no available treatment.
\end{abstract}

\section{Introduction}

Drug addiction is a chronic illness that remains a major public heath problem. Among drugs of abuse, cocaine is one of the most addictive substances in use today. It binds to the dopamine transporter (DAT) and blocks the presynaptic uptake of dopamine (DA), mediating the behavioural and reinforcing effects that contribute to its abuse liability. Analysis of the DAT-binding sites shows an upregulation in post mortem brains of cocaine addicts and in acutely abstinent cocainedependent individuals (Lee et al., 2001; Mash et al., 2002). Therefore, long-term cocaine abuse leads to neuroadaptive changes in DA homeostasis and in the mesolimbic dopaminergic system, the critical pathway mediating addiction to psychostimulant and reinforcement.

The synaptic protein, $\alpha$-synuclein, is an important regulator in dopaminergic transmission (Abeliovich et al., 2000; Mosharov et al., 2006). Synucleins are small, soluble proteins expressed primarily in neural tissue and in certain tumours. The family includes three known proteins: $\alpha$-synuclein, $\beta$-synuclein and $\gamma$-synuclein (George, 2001; Li et al., 2002). $\alpha$-Synuclein plays a role on synaptic vesicular transport and synaptic plasticity (Bennett et al., 1999; Murphy et al., 2000), and has a fundamental function in the genesis of neurodegenerative disorders (Cooper et al., 2006). It is a major component of Lewy body in sporadic forms of Parkinson's disease, and its overexpression is implicated in the aetiology of Parkinson's and Alzheimer's diseases (Lotharius \& Brundin, 2002). Two mutant forms (A53T and A30P) are

Correspondence: Professor J.-L. Dreyer, as above.

E-mail: jean-luc.dreyer@unifr.ch linked to the familiar form of Parkinson's disease (Polymeropoulos et al., 1997; Kruger et al., 1998; George, 2001; Goedert, 2001). Furthermore, it is highly expressed in dopaminergic neurons (Abeliovich et al., 2000; Perez \& Hastings, 2004; Yavich et al., 2004) and is involved in DA homeostasis, downregulating the activity of tyrosine hydroxylase and other DA synthesis genes, such as GTP cyclohydrolase (Sidhu et al., 2004a). $\alpha$-Synuclein also binds to the DAT and serotonin transporters, and affects their activities and their recruitment to the plasma membrane (Wersinger \& Sidhu, 2003, 2005; Wersinger et al., 2003, 2006). The shuttling of DAT to and away from the plasma membrane is modified by the action of $\alpha$-synuclein, thereby changing the efficiency of DA uptake at the nerve terminals (Sidhu et al., 2004b).

We have described $\alpha$ - and $\gamma$-synuclein overexpression in the mesolimbic dopaminergic pathway upon psychostimulants (BrenzVerca et al., 2003). Furthermore, an overexpression of $\alpha$-synuclein in DA neurons is observed in cocaine abusers (Mash et al., 2003) or following methamphetamine administration (Maucelli et al., 2006). $\alpha$-Synuclein protein was increased in striatal synaptosomes from cocaine users compared with age-matched drug-free controls (Yujing et al., 2005). On the other hand, an increase in expression of $\alpha$-synuclein mRNA in alcohol-dependent patients within the withdrawal state has been observed and has been associated with an increase in alcohol craving (Weiss et al., 1993; Liang et al., 2003; Bonsch et al., 2004, 2005). Interestingly, $\alpha$-synuclein and DA metabolism play convergent roles in nigrostriatal toxicity (Fornai et al., 2006), and $\alpha$-synuclein levels are elevated in midbrain DA neurons of chronic cocaine abusers (Mash et al., 2003) and are 
associated with methamphetamine psychosis and dependence (Kobayashi et al., 2004), whereas $\alpha$-synuclein levels are significantly increased in the amygdala and striatum/accumbens (but not in the mesencephalon) of morphine-withdrawn mice (Ziolkowska et al., 2005). Taken together all these findings suggest that $\alpha$-synuclein plays a key role in addiction, regulating the DA-signalling pathway. Co-ordinate transcriptional regulation of DA synthesis genes by $\alpha$-synuclein has been described (Baptista et al., 2003).

The aim of the present study was to investigate the role of $\alpha$-synuclein in the rewarding effects of chronic cocaine administration. For this purpose, a lentivirus driving the rat $\alpha$-synuclein overexpression under the control of a tetracycline regulatable promoter was constructed. Furthermore, three lentiviruses expressing $\alpha$-synucleintargeted siRNAs, aimed at silencing $\alpha$-synuclein mRNA expression, were also constructed. These viruses were tested in vitro and served for in vivo gene transfer, by means of stereotaxic injections into the nucleus accumbens (NAcc) of rat brains. The impact of $\alpha$-synuclein expression on chronic cocaine administration was assessed, using locomotor activity and self-administration (SA) paradigms. Overexpression of $\alpha$-synuclein in the NAcc induced a $45 \%$ increase in locomotor activity and a 1.9-fold increase of cocaine SA, which could be abolished when the same animal was fed doxycycline. Furthermore, local inhibition of $\alpha$-synuclein in the NAcc - efficiently achieved in vivo using lentiviruses expressing $\alpha$-synuclein-specific siRNAs - resulted in significant hypolocomotion activity and a decrease in SA.

\section{Materials and methods \\ Ex vivo methods}

\section{Lentivirus constructions}

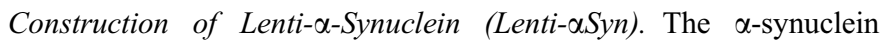
DNA (GenBank accession no. AF007758) was polymerase chain reaction (PCR) amplified using the pGEMT-rat-Alpha-Synuclein as template and the following primers: 5'-CGC GGA TCC GCG ATG GAT GTG TTC ATG AAA-3' and 5'-CCG CTC GAG CGG TTA ATG ATG ATG ATG ATG ATG GGC TTC AGG CTC ATA GTC T-3'. The forward primer contains a BamH-I restriction site followed by the $5^{\prime}$ rat $\alpha$-synuclein DNA-specific sequence; the reverse primer contains the $3^{\prime}$ rat $\alpha$-synuclein DNA-specific sequence, the 6-Histidine epitope sequence (in bold), a stop codon and a Xho-I restriction site. The PCR product was digested with $B a m H-I$ and Xho-I, and cloned into BamH-I/Xho-I restriction sites into pTK431 (Bahi et al., 2005a) that expresses the gene of interest under control of a Tet-Off promotor. The green fluorescent protein (GFP) expression vector pTK433 (Bahi et al., 2004a,b) was used as a control vector.

Construction of Lenti- $\alpha$-synuclein-siRNAs (Lenti- $\alpha$ Syn-siRNA). To silence $\alpha$-synuclein expression in vitro and in vivo, three targets were designed, according to the $\alpha$-synuclein mRNA sequence. The following targets within the $\alpha$-synuclein sequence were selected, based on Hannon's design criterion (http://katahdin.cshl.org:9331/ RNAi/html/rnai.html): first target: bp 36-52; second target: bp 305320; third target: bp 406-423. To each oligo, a Xho-I restriction site was added at $3^{\prime}$, and a U6-3'-specific 10 mer at $5^{\prime}$. Using the pSilencer 1.0-U6 (Ambion, UK) as a template and a U6 promoter-specific forward primer containing $B a m H-I$ restriction site (5'-GCG GAT CCC GCT CTA GAA CTA GTG C-3'), each siRNA target was added to the mouse U6 promoter by PCR, using the following PCR program: $120 \mathrm{~s}$ at $94{ }^{\circ} \mathrm{C}$ (initial denaturation) followed by 35 cycles $\left(45 \mathrm{~s}\right.$ at $94{ }^{\circ} \mathrm{C}$, $45 \mathrm{~s}$ at $64^{\circ} \mathrm{C}$ and $45 \mathrm{~s}$ at $72{ }^{\circ} \mathrm{C}$ ) in $4 \%$ dimethyl sulphoxide (Sigma,
Switzerland). The PCR product was digested with BamH-I and Xho-I, cloned into similar sites into pTK431, and sequenced to verify the integrity of each construct.

\section{Lentivirus production}

The vector plasmids (either pTK431- $\alpha$-Synuclein, pTK433-GFP or pTK431-U6- $\alpha$-Syn-siRNAs), together with the packaging construct plasmid $\mathrm{p} \cdot \mathrm{NRF}$ and the envelope plasmid pMDG-VSV-G were co-transfected into human embryonic kidney (HEK)293T cells to produce the viral particles (Bahi et al., 2004a,b). The viral titres were determined by 24 antigen measurements (KPL, USA). For the in vivo experiments, the different viral stocks were matched for viral particle content and used at $0.2 \mathrm{mg} / \mathrm{mL}$ of $\mathrm{p} 24$.

\section{In vitro $\alpha$-synuclein assays}

The efficiency of the Lenti- $\alpha$ Syn was tested in vitro by infection of HEK293T cells. $1 \times 10^{5}$ HEK293T cells were plated. The next day, lentiviruses stocks were mixed with $4 \mu \mathrm{g} / \mathrm{mL}$ Polybrene (Sigma, Switzerland) with or without $30 \mathrm{ng} / \mathrm{mL}$ doxycycline (Sigma), incubated for $30 \mathrm{~min}$ at room temperature, added to the cells and incubated at $37{ }^{\circ} \mathrm{C}$. After $24 \mathrm{~h}$ the medium was replaced with normal growth medium (with or without $30 \mathrm{ng} / \mathrm{mL}$ doxycycline) and cells were left for a further $48 \mathrm{~h}$. Cells were then collected and used for total RNA isolation (for real-time PCR) or for total protein isolation (Western blot). Infections with the different lentiviruses were done as follows: (a) doxycycline regulation: cells were co-infected using $0,2,4$ or $8 \mu \mathrm{L}$ of Lenti- $\alpha$ Syn stock, and one part of the cells was incubated in the presence of $30 \mathrm{ng} / \mathrm{mL}$ doxycycline and the other part without doxycycline; (b) in vitro silencing of $\alpha$-synuclein: cells were infected with $4 \mu \mathrm{L}$ of Lenti- $\alpha$ Syn stock, either alone or together with $2 \mu \mathrm{L}$ of Lenti- $\alpha$ Syn-siRNA T1, $2 \mu \mathrm{L}$ of Lenti- $\alpha$ Syn-siRNA T2, $2 \mu \mathrm{L}$ of LentiaSyn-siRNA T3, or with 2 or $4 \mu \mathrm{L}$ of all three targets together (mix of Lenti- $\alpha$ Syn-siRNA T1, Lenti- $\alpha$ Syn-siRNA T2 and Lenti- $\alpha$ Syn-siRNA T3).

\section{Quantitative real-time PCR and quantification of $\alpha$-synuclein transcripts}

For quantitative real-time PCR, primer sets for rat $\alpha$-synuclein, glyceralaldehyde-3-phosphate-dehydrogenase (GAPDH) or $\beta$-actin were designed to amplify 100 - to 200 -bp products, using PRIMER3 software: (http://frodo.wi.mit.edu/cgi-bin/primer3/primer3_http:// www.cgi). The following specific primer pairs were used: $\alpha$-synuclein: 5'-GCG TCC TCT ATG TAG CTT CCA-3' and 3'-AGC AGC AAT GTT CCC AGC; GAPDH: 5'-ATG ACT CTA CCC ACG GCA AG-3' and $5^{\prime}$-CAT ACT CAG CAC CAG CAT CAC-3'; $\beta$-actin: $5^{\prime}$-AGC CAT GTA CGT AGC CAT CC-3' and 5'-CTC TCA GCT GTG GTG GTG AA- $3^{\prime}$. GAPDH and $\beta$-actin were used as endogenous controls for normalization. No difference in expression was observed between these two genes in all quantifications.

Total RNA was extracted from the HEK293T cells (for in vitro quantification) and from brains of cocaine-treated animals (for in vivo quantification) using TRIzol Reagent (Invitrogen), including an RNase-free DNase step. RNA was quantified by spectrophotometry, and its integrity verified by agarose gel electrophoresis as visualized with ethidium bromide staining. First-strand cDNA was generated from $2 \mu \mathrm{g}$ total RNA and Oligo( $\left.\mathrm{dT}_{12-18}\right)$-primer with the M-MLV reverse transcription kit (Invitrogen) in a total volume of $20 \mu \mathrm{L}$. The reaction product was used for quantitative real-time PCR using the real-time PCR iCycler (Bio-Rad, Switzerland). cDNA preparation $(2 \mu \mathrm{L}), 0.5 \mu \mathrm{M}$ of forward and reverse primers, and $10 \mu \mathrm{L}$ of IQ SYBR Green Supermix (Biorad) in a total volume of $20 \mu \mathrm{L}$ were 
applied, and PCR was performed as follows: $3 \mathrm{~min}$ at $95{ }^{\circ} \mathrm{C}$ (initial denaturation); $20{ }^{\circ} \mathrm{C} / \mathrm{s}$ temperature transition rate up to $95{ }^{\circ} \mathrm{C}$ for $45 \mathrm{~s}, 62^{\circ} \mathrm{C}$ for $45 \mathrm{~s}$, repeated 40 times (amplification). The PCR reaction was evaluated by melting curve analysis and by checking the PCR products on $2 \%$ agarose gel.

The PCR cycle number at which each assay target reached the threshold detection line was determined ('threshold cycles', $C_{\mathrm{t}}$ value). The $C_{\mathrm{t}}$ of each gene was normalized against that of GAPDH or $\beta$-actin. To determine the linearity and detection limit of the assay, cDNA samples were amplified for successive 10-fold dilutions in a series of real-time PCRs, using a duplicate assay on each dilution, so that the correlation coefficient could be calculated from the standard curve of $C_{\mathrm{t}}$ values. Comparisons were made between cocaine and saline groups, and significance was calculated using two-tailed Student's $t$-test, and the level of statistical significance was set at $P<0.05$. Data were expressed as means $\pm \mathrm{SEM}$. The $\cdot C_{\mathrm{t}}$ for each candidate was calculated as: $C_{\mathrm{t}}=\left[C_{\mathrm{t}}\right.$ (candidate) $-C_{\mathrm{t}}(\mathrm{GAPDH}$ or $\beta$-actin $\left.)\right]$.

The relative abundance of each target in each protocol can be calculated as the ratio between treated and untreated samples (Bahi \& Dreyer, 2004; Bahi et al., 2004b).

\section{Western blotting}

Rat NAcc (150-200 mg) or transfected HEK293T cells were homogenized in buffer (in mM: Tris, $50, \mathrm{pH} \mathrm{7.5;} \mathrm{NaCl}, 120 ; \mathrm{CaCl}_{2}, 1.5$; $\mathrm{MgCl}_{2}, 5 ; \mathrm{KCl}, 5$; EDTA, 5) with a protease inhibitor mixture (Sigma, St Louis, MO, USA; $1 \mathrm{~mL} / 20 \mathrm{~g}$ of tissue). Homogenates were solubilized with $1 \%$ digitonin, followed by the addition of secondary solubilization buffer [in mM: Tris, 50, pH 7.6; NaCl, 150;1\% Nonidet-P40; $0.5 \%$ sodium deoxycholate; EDTA, 2; sodium orthovanadate, 1 ; phenylmethylsulphonyl fluoride (PMSF), 1; 1\% Triton X100], and centrifuged at $10000 \mathrm{~g}$ at $4{ }^{\circ} \mathrm{C}$ for $15 \mathrm{~min}$. Solubilized extracts were subjected to sodium dodecyl sulphate-polyacrylamide gel electrophoresis (SDS-PAGE). Blots were blocked with 5\% non-fat dried milk dissolved in Tris-Buffered Saline Tween-20 (TBST) (in mM: Tris, $10 ; \mathrm{NaCl}, 150 ; 0.1 \%$ Tween-20) for $1 \mathrm{~h}$ at room temperature, and incubated with primary antibodies for either 6-His (1:2000, ABCam, ab5000) or $\alpha$-synuclein (1:1000, ABCam, ab1904) for $10-12 \mathrm{~h}$ at $4{ }^{\circ} \mathrm{C}$. Blots were washed three times with TBST and incubated for $1 \mathrm{~h}$ with the peroxidase-conjugated secondary antibody solution. Proteins were then visualized using enhanced chemiluminescence (Millipore). Membranes were washed for $30 \mathrm{~min}$ in TBST and placed in stripping solution (glycine- $\mathrm{HCl} 25 \mathrm{~mm}$, $\mathrm{pH} 2.0,1 \%$ SDS) for $30 \mathrm{~min}$ and used as described above for $\beta$-actin detection. (1: 4000, Sigma). Signals were detected with a Fluorchem tm 8900 apparatus (Alpha Innotech), and the TIFF pictures were quantified with the multianalyst software (Biorad).

\section{Immunohistochemistry}

For immunohistochemistry assays, rats were decapitated. Brains were quickly removed from the skull, immediately frozen in isopentane (at $-30{ }^{\circ} \mathrm{C}$ for $3 \mathrm{~min}$ ) and kept at $-25^{\circ} \mathrm{C}$. Coronal sections were cut at $14 \mu \mathrm{m}$ in a cryostat and placed on gelatinized glass slides, air-dried at room temperature for $20 \mathrm{~min}$ and kept at $-25^{\circ} \mathrm{C}$ until further processing.

Brain sections were fixed for $10 \mathrm{~min}$ in cold acetone and washed three times in $1 \times$ phosphate-buffered saline (PBS). Non-binding sites were blocked by incubating slices for $1 \mathrm{~h}$ in $1 \times$ PBS containing $1 \%$ bovine serum albumin, $1 \%$ Triton $\mathrm{X}-100$ and $3 \%$ normal goat serum. Sections were then incubated overnight at $4{ }^{\circ} \mathrm{C}$ with primary antibodies specifically against either $\alpha$-synuclein (mouse anti- $\alpha$-synuclein antibody, ABCam ab1904, $1: 5000)$, 6-His (mouse anti-histidine antibody, MCA1396, Serotec, $1: 5000$ ), NeuN (mouse anti-neuronal-nuclei, MAB 377, Chemicon, $1: 5000$ ) or synaptophysin (mouse anti-synaptophysin, Chemicon, MAB329, $1: 1000)$. Antibodies were diluted in $1 \times$ PBS containing $0.1 \%$ Triton $\mathrm{X}-100$ and $1 \%$ normal goat serum. Thereafter, slices were washed three times in $1 \times \mathrm{PBS}$, and incubated for $2 \mathrm{~h}$ in the secondary antibody (Texas red-conjugated goat anti-mouse immunoglobulin $\mathrm{G}, 1: 500$ ) or (FITC-conjugated goat anti-mouse IgG, $1: 500$ ) in $1 \times$ PBS containing $0.1 \%$ Triton $\mathrm{X}-100$. The sections were coverslipped with a medium containing glycerol in PBS (AF1 mounting solution, Citifluor).

Negative controls included omission or substitution of primary antibodies.

Fluorescence microscopy. To observe the stained sections, a multifluorescence microscope (Axioplan 2 imaging; Zeiss) was used with a $40 \times$ or $100 \times$ objective. Fluorophores (FITC and Texas red) used were detected with the appropriate detecting systems (HAL 100). FITC was excited at $495 \mathrm{~nm}$ and was detected through a light path ranging $510-550 \mathrm{~nm}$. Texas red was exited at $570 \mathrm{~nm}$ and was detected through a light path ranging 600-660 nm. Stained sections were visualized, photographed using a multichannel camera (Axiocam, Zeiss) combined with acquisition software (Axiovision system 3.1) and recorded on CD.

\section{In vivo methods}

\section{Animal handling and behavioural analysis}

Animals used in this experiment were male Wistar rats weighing 250280 g. All animal experiments were carried out in accordance with the guidelines and regulations for Animal Experimentation, BAG, Bern, Switzerland. The animals were housed four per cage, in clear plastic cages with wire grid lids. Access to food and water was unrestricted. The animals were kept in the animal facility maintained on a $12 \mathrm{~h}$ light : dark cycle (lights off at $07.00 \mathrm{~h}$ ). At the end of each in vivo experiment, the animals were decapitated, and brains removed for analysis.

For doxycycline treatment, animals were maintained with $0.02 \%$ doxycycline (Sigma) and 5\% sucrose supplemented in water. During the gene overexpression period, animals were maintained only with $5 \%$ sucrose.

\section{Stereotaxic surgery}

Stereotaxic surgery and injection of the lentiviral vector were performed according to previous publications (Bahi et al., 2004a,b). Rats were anesthetized with ketamine-xylazine $(10 \mathrm{mg} / \mathrm{kg}$ and $0.1 \mathrm{mg} / \mathrm{kg}$ ) administered i.p. Animals were bilaterally injected into the NAcc with $2 \mu \mathrm{L}$ of concentrated lentiviral stock $(0.2 \mathrm{mg} / \mathrm{mL}$ of $\mathrm{p} 24$, corresponding to $8 \times 10^{9} \mathrm{IU} / \mathrm{mL}$ ). The injections were performed bilaterally at the following coordinates, as calculated from bregma and the dura mera: anterior +1.4 ; lateral \pm 1.2 ; ventral -6.8 (Paxinos \& Watson, 1998).

\section{Intravenous surgery}

Wistar rats (250-280 g) were individually housed under a constant $12 \mathrm{~h}$ light : dark cycle (lights off at $07.00 \mathrm{~h}$ ) with free access to food and water. Under anaesthesia, a SILASTIC catheter $(15 \mu \mathrm{L}$ dead volume) was inserted in the external jugular vein. Rats were anaesthetized with a cocktail mixture of ketamine $(10 \mathrm{mg} / \mathrm{kg})$ and xylazine $\mathrm{HCl}(0.1 \mathrm{mg} / \mathrm{kg})$ administered i.p. in a volume of $1 \mathrm{~mL} / \mathrm{kg}$. The surgical procedure consisted of making an incision between the breastbone and the clavicle to expose the jugular vein. 
The catheter was inserted into the jugular vein and secured with sutures. The catheter was then passed under the skin and fixed in the mid-scapular region. For the first 3 days after surgery, the catheters were flushed daily with $0.1 \mathrm{~mL}$ of saline mixed with heparin $(100 \mathrm{U} / \mathrm{mL})$ and gentamicin $(1 \mathrm{mg} / \mathrm{kg})$. Thereafter, the catheters were flushed with a saline-heparin mixture after each session. Standard operant chambers (Coulbourn Instruments, Allentown, PA, USA) housed in ventilated sound-attenuating cubicles (Coulbourn Instruments) with fans to mask outside noise were utilized for the SA. One response lever with three 'cue' lights above was located on one wall of each chamber. Close to the lever was a recessed food receptacle into which food pellets $(45 \mathrm{mg}$ each; Bio-Serv, Frenchtown, NJ, USA) could be dispensed from a pellet dispenser. A house light was also located within the chamber. These chambers were equipped with syringe pump systems, which consisted of an infusion pump (Razel model A-99; Stamford, CT, USA) with a 10-mL plastic syringe connected by a single-channel 22-gauge swivel (Instech Laboratories; Plymouth Meeting, PA, USA) with Teflon tubing. The tubing could be connected to the animal's catheter system in order to deliver cocaine solution. Graphic State Notation (Coulbourn Instruments) was used to program experimental parameters (e.g. schedules of reinforcements, time periods, etc.), and tabulate and store session data.

\section{Procedures}

Experiment 1: cocaine-induced locomotion. Four groups of animals $(n=6)$ were prepared: one group was stereotaxically injected with $2 \mu \mathrm{L}$ of Lenti-GFP (controls); one group was stereotaxically injected with $2 \mu \mathrm{L}$ of Lenti- $\alpha$ Syn; a third group was injected with $2 \mu \mathrm{L}$ of a mix of all three Lenti- $\alpha$ Syn-siRNA; and the fourth group was injected with $2 \mu \mathrm{L}$ Lenti- $\alpha$ Syn together with $2 \mathrm{~mL}$ of a mix of the three LentiaSyn-siRNA. Seven-12 days after stereotaxic surgery, locomotor activity was monitored in daily sessions over $3 \times 5$ days in $43.2 \times 43.2 \mathrm{~cm}$ MED-OFA-RS cages (MED Associates, USA) during the dark cycle, according to previously published procedures (Bahi et al., 2004a,b). Animals were daily injected cocaine i.p. and were fed without doxycycline for 5 days (Session A), then fed doxycycline for 7 days (Session B), and finally fed without doxycycline for 7 days (Session C). Locomotor activity was recorded on Days 1-5, 8-12 and 15-19; over the 2-day periods between sessions - necessary for full doxycycline-mediated switch of ectopic $\alpha$-synuclein expression - no measurements were performed (Table 1). Prior to each locomotor activity measurements, the animal was injected with $0.9 \%$ saline, and placed into the activity-monitoring cage for a $15 \mathrm{~min}$ baseline. After this 15 -min period, the session automatically paused for a few seconds and, during this interval, each subject received cocaine-HCl (Sigma, $15 \mathrm{mg} / \mathrm{kg}$, i.p.) and was then placed back into the locomotor activitymonitoring cage for a further $60 \mathrm{~min}$. Statistical evaluation of behavioural analysis was performed according to previous publications (see Bahi et al., 2004a,b). At the end of the third session (Session C) half of the animals were killed. The other half were switched back on doxycycline for $48 \mathrm{~h}$ then killed. All animals were killed by decapitation. During this switch period, animals were still daily administered cocaine and, as for the other group, were killed $24 \mathrm{~h}$ after the last cocaine injection. Brains were used either for immunocytochemistry or quantitative real-time PCR.

Two additional groups $(n=8)$ of naïve animals, one fed doxycycline for 5 days, were also killed and their brains dissected. These groups received no cocaine and no lentivirus treatment, and their brain part served as controls for evaluation of cocaine-induced expression of $\alpha$-synuclein in other groups in quantitative real-time PCR measurements.

Experiment 2: cocaine-induced intravenous SA. Prior to surgery, rats were food-restricted to $85 \%$ of free feeding body weight and trained to lever-press for food reinforcement using a fixed ratio (FR)1 schedule of reinforcement during 60-min sessions. Training continued until the animal earned the constant number of reinforcers for two consecutive days. After this training period and a sufficient time to regain weight lost during food restriction, the stereotaxic and the intravenous catheter surgeries were performed at the same time. Four different groups of animals, stereotaxically injected like in Experiment 1, were prepared $(n=9)$ ). After 7 days of recovery, rats were tested for cocaine SA. They were placed into the operant chambers, connected to the catheter/cannula system, and allowed to SA cocaine during daily 1-h sessions. Testing started $2 \mathrm{~h}$ after lights off. One depression of the active lever (FR1) resulted in an intravenous infusion of $20 \mu \mathrm{L}$ of a solution containing $0.7 \mathrm{mg} / \mathrm{kg}$ of cocaine. The cocaine infusion was delivered over a 2 -s period followed by a 40 -s time out. Active lever presses that were emitted during the infusion time or during the time out period were tabulated but did not result in any further cocaine delivery. During the infusion, the house light was turned off, and the cue lights over the active lever were illuminated. During the time out period the house light was turned on and the cue lights were switched off. The criterion for acquisition of cocaine SA was defined by a stable number of selfinfusions over at least three consecutive sessions $( \pm 20 \%)$. When cocaine showed control over behaviour under the FR1 schedule of reinforcement, the FR requirement was raised to FR2, FR3 and then to FR5, the schedule used for the remainder of the experiment.

TABLE 1. Summary of experimental protocol for each group of animals in Experiment 1

\begin{tabular}{|c|c|c|c|c|c|c|c|c|c|c|c|c|c|c|c|c|c|c|c|c|c|c|}
\hline \multirow[b]{3}{*}{ Days 1-22: } & \multicolumn{22}{|c|}{ Sessions } \\
\hline & \multicolumn{5}{|l|}{ A } & \multicolumn{2}{|c|}{ Switch } & \multicolumn{5}{|l|}{ B } & \multicolumn{2}{|c|}{ Switch } & \multicolumn{5}{|l|}{$\mathrm{C}$} & \multicolumn{3}{|l|}{ End or switch } \\
\hline & 1 & 2 & 3 & 4 & 5 & 6 & 7 & 8 & 9 & 10 & 11 & 12 & 13 & 14 & 15 & 16 & 17 & 18 & 19 & 20 & 21 & 22 \\
\hline \multicolumn{23}{|c|}{ Doxycycline $(+/-)$} \\
\hline Group 1 & - & - & - & - & - & + & + & + & + & + & + & + & - & - & - & - & - & - & - & - End $(n=4)$ & & \\
\hline Group 2 & - & - & - & - & - & + & + & + & + & + & + & + & - & - & - & - & - & - & - & & + & + End $(n=4)$ \\
\hline Group 3 & - & - & - & - & - & + & + & + & + & + & + & + & - & - & - & - & - & - & - & - End $(n=4)$ & & \\
\hline Group 4 & - & - & - & - & - & + & + & + & + & + & + & + & - & - & - & - & - & - & - & + & + & + End $(n=4)$ \\
\hline Measurement & + & + & + & + & + & - & - & + & + & + & + & + & - & - & + & + & + & + & + & - & - & - \\
\hline
\end{tabular}

See the Materials and methods section for details. At the end of the experiment the animals were killed and the brains used either for immunocytochemistry or quantitative real-time PCR. 
As in Experiment 1, half of the animals were killed by decapitation $24 \mathrm{~h}$ after the last cocaine SA session, while the remaining $(n=5)$ were fed doxycycline for $48 \mathrm{~h}$ before being killed. During this switch period, animals were still daily tested and, as for the other group, were killed $24 \mathrm{~h}$ after the last cocaine SA session. Brains were used either for immunocytochemistry, Western blot or quantitative real-time PCR analysis.

\section{In vivo assays of $\alpha$-synuclein}

The efficiency of the lentivirus-mediated $\alpha$-synuclein expression in vivo was assessed by stereotaxic injection, into the NAcc, of Lenti- $\alpha$ Syn stock alone in a first group of animals, or Lenti- $\alpha$ Syn together with Lenti- $\alpha$ Syn-siRNAs mix in a second group of animals. To suppress endogenous $\alpha$-synuclein expression, a third group of animals were infected only with $2 \mu \mathrm{L}$ of Lenti- $\alpha$ Syn-siRNAs mix. Finally, a control group of animals was injected in the same brain area with Lenti-GFP. After surgery, animals were left for recovery for 7 days. At the end of the behavioural analysis (locomotor activity or SA), some of the animals were killed by decapitation $24 \mathrm{~h}$ after the last cocaine injection, while the remaining animals were fed doxycycline for $48 \mathrm{~h}$ before being killed. During this switch period, animals were still daily administered cocaine and, as for the other group, were killed $24 \mathrm{~h}$ after the last cocaine injection. Brains were either homogenized for protein or quantitative real-time PCR analysis, or dissected out for immunohistochemistry analysis. For molecular analysis, brains were dissected out and the NAcc, striatum and ventral tegmental area (VTA) regions were isolated. Tissues were used for RNA extraction using TRIzol Reagent (Invitrogen) or for protein extraction.

\section{Statistical analyses}

Two-way ANOvA was used to compare both lentiviral and drug treatment in the presence or absence of doxycycline, using GraphPad PRISM (V3.0, GraphPad, San Diego, California, USA). For locomotor activity two-way ANOVA was used, with time as the within-subject factors and lentiviral treatment as the between-subject factors followed by Bonferroni post hoc tests. For SA and real-time PCR analysis, two-way ANOVAs were used with drug treatment (water vs doxycycline) as the within-subject factors and lentiviral treatment as the between-subject factors followed by Bonferroni post hoc tests.

\section{Results}

\section{Lentivirus-mediated $\alpha$-synuclein expression in HEK293T cells}

$\alpha$-Synuclein was cloned into a tetracycline-regulatable lentivirus system. The lentivirus expressing $\alpha$-synuclein (Lenti- $\alpha$ Syn) was used for in vitro assays (see Materials and methods). HEK293T cells were infected with different amounts of virus (Fig. 1A), and $\alpha$-synuclein mRNA was measured by real-time PCR. As shown, Lenti- $\alpha$ Syn induced $\alpha$-synuclein gene and protein expression in a dose (titre)dependent manner. Using 2, 4 and $8 \mu \mathrm{L}$ of viral stock, $\alpha$-synuclein mRNA increased by $4.7-, 8.8-$ and 12.6 -fold $\left(F_{6,28}=32.81\right.$, $P<0.001)$, respectively. This induction is completely reversible in the presence of doxycycline, which blocks lentivirus-mediated $\alpha$-synuclein overexpression, both at the mRNA (Fig. 1A) and the protein levels (Fig. 4). For real-time PCR, $\alpha$-synuclein transcripts levels were normalized against $\beta$-actin used as endogenous control. GAPDH expression, an endogenous control, is unaffected by lentivirus-mediated gene transfer (Fig. 1A and $\mathrm{B}$ )

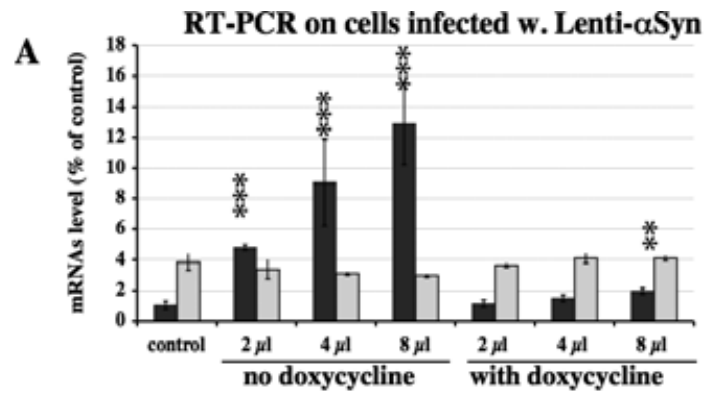

RT-PCR on cells infected w. Lenti- $\alpha$ Syn + Lenti- $\alpha$ Syn-siRNAs

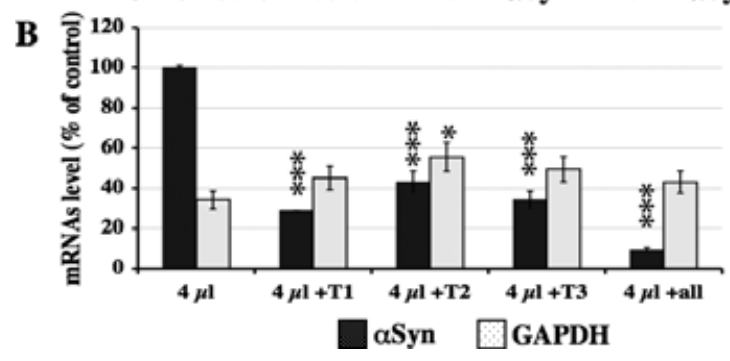

FIG. 1. Quantification of in vitro expression of $\alpha$-synuclein mRNA in HEK293T cells using quantitative real-time polymerase chain reaction (PCR). (A) Dose-response effects of Lenti- $\alpha$ Syn. HEK293T cells were infected with $0,2,4$ or $8 \mu \mathrm{L}$ Lenti- $\alpha$ Syn in culture medium in the presence or absence of doxycycline $(30 \mathrm{ng} / \mathrm{mL})$, as indicated. After $96 \mathrm{~h}$, culture medium was removed and cells were used for total RNA extraction, cDNA preparation and quantitative real-time PCR using specific oligos. Results were normalized against GAPDH used as endogenous control. Normalized transcript levels were from cells infected without doxycycline. Control: non-infected HEK293 cells. $* P<0.05, * * P<0.01$ and $* * * P<0.005$ vs non-infected cells. (B) Silencing efficiency of Lenti- $\alpha$ Syn-siRNAs. HEK293T cells were infected with $4 \mu \mathrm{L}$ Lenti- $\alpha$ Syn with or without other viruses, as indicated. After $96 \mathrm{~h}$, culture medium was removed and cells were used for total RNA extraction, cDNA preparation and quantitative real-time PCR using specific sets of primers. Results were normalized vs GAPDH as endogenous control. ${ }^{* *} P<0.05$ and ${ }^{* * *} P<0.005$ vs cells infected with Lenti- $\alpha$ Syn.

\section{SiRNAs-expressing lentiviruses and $\alpha$-synuclein silencing in vitro}

In order to knockdown $\alpha$-synuclein expression, lentivirus-based RNA interference was used. Three different siRNAs were designed, cloned into the lentiviral transfer plasmid (Lenti- $\alpha$ Syn-siRNAs T1, T2 and T3) and their silencing efficiency was assessed in vitro in Lenti- $\alpha$ Syninfected HEK293T cells (Fig. 1B). Target specificity was controlled by co-infections of HEK293T cells with Lenti-GFP. Ninety-six hours after infection, cells were harvested, total RNA was extracted and transcripts levels were measured by means of quantitative real-time PCR using specific primers for each candidate. All normalizations were performed against $\beta$-actin (no significant difference was observed when GAPDH instead of $\beta$-actin was used for normalization, $P>0.05)$. Cells co-infected with Lenti- $\alpha$-Syn were set-up to $100 \%$ of $\alpha$-synuclein expression level (Fig. 1B; ' $4 \mu \mathrm{L}$ '). When Lenti-GFP was also added during co-infection no significant change of $\alpha$-synuclein mRNA levels was observed, yielding $\sim 98 \%$ of $\alpha$-synuclein transcripts, vs $100 \%$ in controls (data not shown). In contrast, co-infection with Lenti- $\alpha$ Syn-siRNAs T1, T2 and T3 resulted in drastic $\alpha$-synuclein downregulation, yielding $29.1 \%, 43.1 \%$ and $34.2 \%$ residual $\alpha$-synuclein expression levels, respectively. (Fig. 1B; $\left.F_{4,20}=22.70, P<0.01\right)$. Co-infection in the presence of all three Lenti- $\alpha$ Syn-siRNAs together resulted in $90.8 \% \alpha$-synuclein mRNA knockdown (Fig. 1B; ' $4 \mu \mathrm{L}+$ all', $P<0.01$ ). Under all conditions, the expression levels of other genes (e.g. GAPDH; Fig. 1B) were not 
affected by Lenti- $\alpha$ Syn-siRNAs, indicating that the targets are highly $\alpha$-synuclein specific.

Western blot analysis, using either anti- $\alpha$-synuclein antibody or anti-6His antibody, showed that protein expression highly correlates with transcripts levels (Fig. 2). Quantification from 6-His-based Western blots shows that co-infection of Lenti- $\alpha$ Syn with T1, T2 or T3 resulted in $12 \%, 22 \%$ and $3 \%$ residual $\alpha$-synuclein, respectively, whereas co-infection of Lenti- $\alpha$ Syn with all three Lenti- $\alpha$ Syn-siRNAs together resulted in $<4 \%$ residual $\alpha$-synuclein (Fig. $2 ; F_{6,28}=23.07$, $P<0.001)$.

\section{In vivo cocaine-mediated $\alpha$-synuclein expression and silencing}

Four groups of animals $(n=8)$, stereotaxically injected with different combinations of lentiviruses, were prepared and behaviour was measured in three 5-day sessions (locomotor activity or SA, see Materials and methods, and Table 1). Animals received daily cocaine injections. During the first 5-day session ('Session A') animals were fed without doxycycline during five consecutive days, and then switched to the doxycycline regimen for 7 days, but the behavioural analysis was performed only 2 days after the switch, for five consecutive days ('Session B'). Finally, animals were switched again without doxycycline and measured 2 days later for five consecutive days ('Session C'). At the end of the behavioural analyses, half of the animals from each group were killed, the second half of the animals was fed doxycycline for $48 \mathrm{~h}$ (turning off $\alpha$-synuclein overexpression
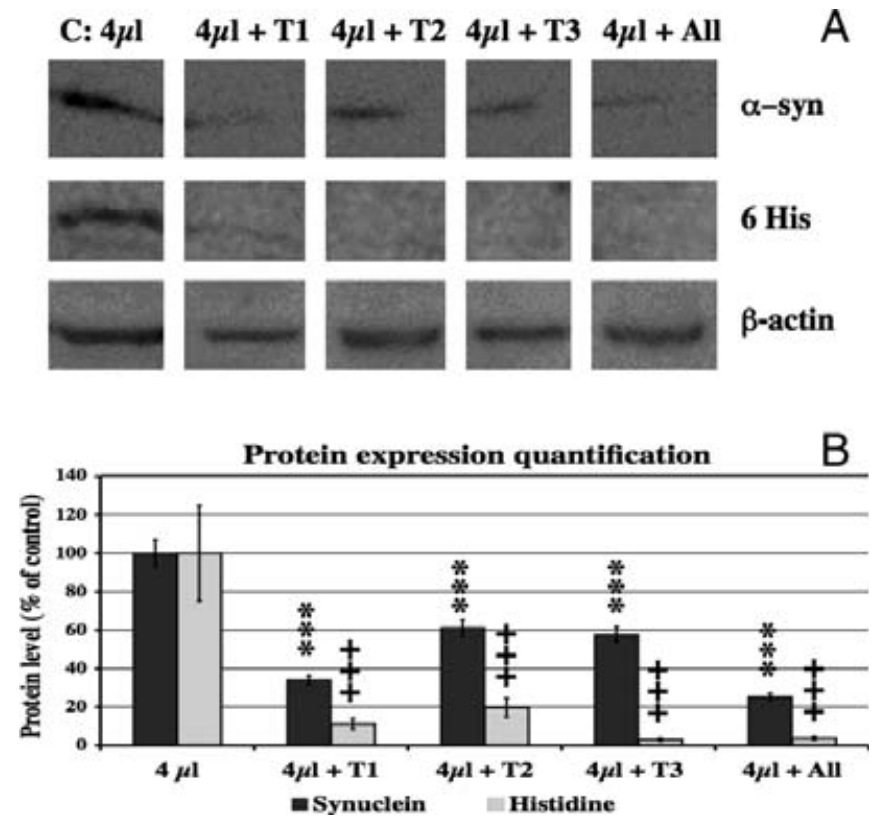

FIG. 2. Expression of $\alpha$-synuclein in the HEK293T cells. Cells were transfected as in Fig. 1. Proteins were extracted as described in Materials and methods, to compare $\alpha$-synuclein expression in different lentivirus infected cells (control $\mathrm{C}$ in left-most column). (A) Immunoblots of $\alpha$-synuclein expression. Western blots from gels loaded with $15 \mu \mathrm{g}$ protein/lane were analysed for $\alpha$-synuclein or 6-histidine expression, and reprobed with anti- $\beta$ actin antibody to compare $\alpha$-synuclein expression in lentivirus-infected cells. (B) Semi-quantitative analysis of Western blot signals. $\alpha$-Synuclein signals were estimated using multianalyst software and normalized against GAPDH signal. $* * * P<0.001 \alpha$-synuclein protein quantification vs cells infected with $4 \mu \mathrm{L}$ Lenti- $\alpha$ Syn; ${ }^{+++} P<0.0016$-histidine quantification vs cells infected with $4 \mu \mathrm{L}$ Lenti- $\alpha$ Syn, two-way ANOVA, Bonferroni post hoc tests. in the NAcc), and then killed. After killing, brains were removed, NAcc tissues were dissected out and used either for total RNA extraction or Western blot analysis to test lentivirus-mediated and cocaine-induced $\alpha$-synuclein expression in vivo.

\section{mRNA expression in vivo}

After reverse transcription, mRNA expression levels were measured by means of quantitative real-time PCR. Data have been normalized with respect to the control groups that consisted of naïve animals not receiving cocaine but fed either with or without doxycycline. These two groups served to assess cocaine-mediated induction of $\alpha$-synuclein. Data are shown in Fig. 3.

When animals have been injected with Lenti-GFP, $\alpha$-synuclein expression was $\sim 3.1$ compared with saline-injected control (Fig. 3; $F_{4,20}=103.03, P<0.01$ ), reflecting cocaine-mediated induction of endogenous $\alpha$-synuclein. Animals of this group switched to doxycycline displayed $\sim 2.5$-fold cocaine-induced increase in $\alpha$-synuclein expression, compared with saline-injected control animals (Fig. 3; $P>0.05, F_{4,20}=103.03$ ), a ratio not significantly different from the corresponding group fed without doxycycline. The ratios of other targets, e.g. $\beta$-actin mRNA, remained unchanged over saline-treated control animals in both cases.

When animals were injected with only Lenti- $\alpha$ Syn, strong induction of $\alpha$-synuclein mRNA expression was observed in the absence of doxycycline, with a ratio of $\sim 12.3\left(F_{4,20}=103.03, P<0.001\right)$ compared with saline-treated controls (Fig. 3). This expression level dropped 3.3-fold with doxycycline, up to a ratio of 3.7 (compared with naïve controls), equivalent to the ratio observed for GFP-treated animals $\left(F_{4,20}=103.03, P<0.01\right)$. $\beta$-Actin mRNA expression was not affected, and ratios of $\sim 1.5$ and $\sim 1.3$, respectively (no doxycycline), and $\sim 1.6$ and $\sim 2.8$, respectively (with doxycycline), were found for cocaine- and saline-treated animals under these conditions

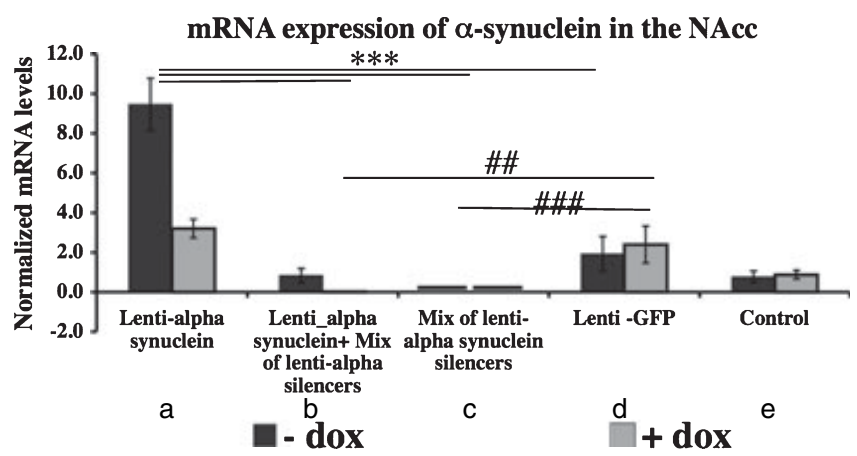

FIG. 3. In vivo overexpression and silencing of $\alpha$-synuclein mRNA in the nucleus accumbens (NAcc) after infection with Lenti- $\alpha$ Syn and/or Lenti- $\alpha$ SynsiRNAs: quantification of transcripts by means of quantitative real-time PCR. Animals $(n=8)$ were bilaterally injected into the NAcc with either: (a) Lenti$\alpha$ Syn alone; (b) Lenti- $\alpha$ Syn combined with a mix of all Lenti- $\alpha$ Syn-siRNAs; (c) a mix of Lenti- $\alpha$ Syn-siRNAs; or (d) Lenti-green fluorescent protein (GFP); and (e) untreated animals (as a control). At the end of the behavioural analysis (locomotor activity), part of the groups used were killed by decapitation $24 \mathrm{~h}$ after the last injection; the NAccs were dissected out and used for total RNA isolation, cDNA preparation and quantitative real-time PCR using specific oligos. Results were normalized against GAPDH. $* * *$ Represents points significantly different from Lenti- $\alpha$ Syn-infected rats $(* * * P<0.001)$. \#epresent points significantly different from Lenti-GFP-injected rats. $\left({ }^{\#} P<0.01 ;{ }^{\# \#} P<0.001\right)$ Two-way ANOvA, Bonferroni post hoc tests. 
$\left(F_{4,20}=103.03, P<0.01\right)$, similar to those observed in the LentiGFP-treated group.

When animals have been injected with Lenti- $\alpha$ Syn together with a mix of Lenti- $\alpha$ Syn-siRNAs, drastic inhibition of $\alpha$-synuclein expression is found in the absence of doxycycline, resulting in a ratio of $\sim 1.1\left(F_{4,20}=103.03, P<0.01\right)$ compared with naïve controls, i.e. at least 11-fold inhibition (Fig. 3). With doxycycline, complete inhibition of $\alpha$-synuclein was found, with ratios $\sim 0.01$ compared with naïve controls $\left(F_{4,20}=103.03, P<0.001\right)$. Indeed, doxycycline blocks exogenous, lentivirus-mediated $\alpha$-synuclein overexpression (but not endogenously expressed $\alpha$-synuclein), while silencers also block endogenous $\alpha$-synuclein. Under these conditions, the other targets ( $\beta$-actin, etc.) were not modified at all, indicating that Lenti$\alpha$ Syn-siRNAs had no effects on their expression levels.

Finally, when animals have been injected with the Lenti- $\alpha$ SynsiRNAs only (without Lenti- $\alpha$ Syn), the $\alpha$-synuclein mRNA expression level dropped up to $\sim 0.007(P<0.001)$ and even to $\sim 0.003$ with doxycycline $\left(F_{4,20}=103.03, P<0.001\right)-$ corresponding to full silencing of endogenous $\alpha$-synuclein mRNA expression - whereas $\beta$-actin was not modified. This value, compared with that observed in the Lenti-GFP-treated group, indicates that a $>99 \%$ knockdown of the endogenous $\alpha$-synuclein has been achieved. As described previously (Bahi et al., 2004a,b, 2005a,b), the use of a mix of three lentivirus silencers most often warrants optimal gene silencing, as requested for observation of solid behavioural changes.

\section{Protein expression in vivo}

Protein expression was assessed from the NAcc of treated animals after behavioural analysis (see Table 1). After killings, brains were dissected out, and the NAccs were used for Western blot analysis (Fig. 4).

Cocaine induces an approximate 1.8-fold increase in $\alpha$-synuclein expression in naïve (control) animals not injected with any lentivirus (Fig. 4), in agreement with previous publications (Brenz-Verca et al., 2003). In the absence of doxycycline, Lenti- $\alpha$ Syn-treated animals display a 7.3-fold higher expression of ectopic $\alpha$-synuclein after chronic cocaine treatment (Fig. $4 ; 100 \%, P<0.001, F_{3,16}=239.68$ ), but this expression level is reduced by $70 \%$ in the presence of doxycycline. Animals treated with both Lenti- $\alpha$ Syn and Lenti- $\alpha$ SynsiRNAs display $22 \%$ and $6 \%$ expression in the presence or absence of doxycycline $\left(P<0.001, F_{3,16}=239.68\right)$, compared with the first group (animals treated with Lenti- $\alpha$ Syn only, in the absence of doxycycline). The remaining $\alpha$-synuclein expression reflects cocainemediated endogenous expression of $\alpha$-synuclein, which is almost fully knocked down by Lenti- $\alpha$ Syn-siRNAs, yielding 4-5\% expression only compared with the Lenti- $\alpha$ Syn group and $18 \%$ of the control group only (Fig. $4 ; F_{3,16}=239.68, P<0.001$ ).

Immunohistochemistry was performed on brains from animals treated under similar conditions (Fig. 5). Animals treated with Lenti$\alpha$ Syn display a very strong overexpression of $\alpha$-synuclein in the NAcc (Fig. 5; left panels); under these conditions doxycycline induced a very large ( $>90 \%)$ suppression of $\alpha$-synuclein overexpression in the NAcc. Animals treated with Lenti- $\alpha$ Syn combined with Lenti- $\alpha$ SynsiRNA displayed a strong (>98\%) suppression of $\alpha$-synuclein, although some $\alpha$-synuclein could still be observed (Fig. 5; left-middle panels) that was almost fully abolished when under doxycycline. In contrast, animals treated only with Lenti- $\alpha$ Syn-siRNA, silencing endogenously expressed $\alpha$-synuclein, display $>99 \%$ silencing of endogenous cocaine-mediated $\alpha$-synuclein expression. Cocaine-mediated $\alpha$-synuclein expression could be assessed from the control GFP-

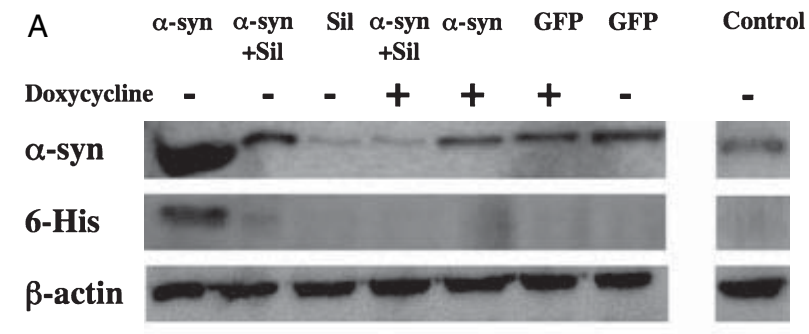

B

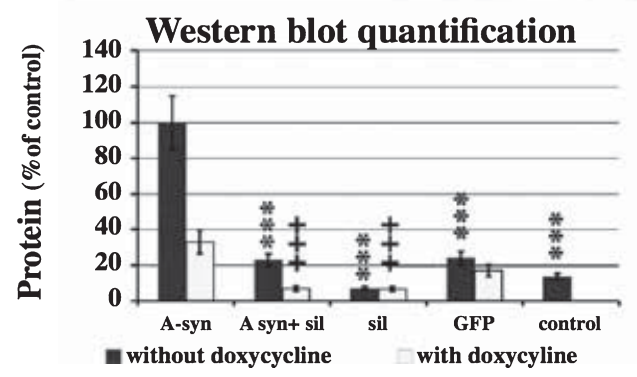

FIG. 4. Expression of $\alpha$-synuclein in the NAcc from lentivirus-injected rats. Animals were prepared as in Fig. 3. Proteins were extracted from the NAcc at the end of each 5-day sessions of locomotor activity, as described in Materials and methods. (A) Immunoblot of $\alpha$-synuclein. Western blots, from gels loaded with $15 \mu \mathrm{g}$ protein/lane, were analysed for $\alpha$-synuclein or 6-histidine expression, and reprobed with anti- $\beta$-actin antibody to compare $\alpha$-synuclein expression in different lentivirus-injected rats. (B) Semi-quantitative analysis of Western blot signals. $\alpha$-Synuclein signals were estimated using multianalyst software and normalized against the GAPDH signal. $* * * P<0.001 \alpha$-synuclein protein quantification vs data from $\alpha$-synuclein-injected rats without doxycycline, ${ }^{++} P<0.001 \alpha$-synuclein protein quantification vs data from $\alpha$-synuclein-injected rats with doxycycline Two-way ANOVA, Bonferroni post hoc tests.

treated group and was not affected by doxycycline treatment (Fig. 5; right panels).

Furthermore, the subcellular localization of $\alpha$-synuclein has been determined via double-immunolabelling. NeuN was used as a specific marker for neuronal nuclei, and synaptophysin was used to detect presynaptic vesicles (Supplementary material, Fig. S1). As shown in Fig. 5, $\alpha$-synuclein was consistently co-expressed with synaptophysin, indicating that the protein is found in presynaptic vesicles. Furthermore, double-immunolabelling of $\alpha$-synuclein and NeuN does not show $\alpha$-synuclein co-localization in the nuclear part of the neurons; under these conditions $\alpha$-synuclein appears rather expressed in a neuritic manner. Taken together these results demonstrate that lentiviral overexpression of $\alpha$-synuclein results in high protein levels that could be abolished by doxycycline treatment. Furthermore, lentiviral-mediated overexpression of $\alpha$-synuclein leads to increased protein levels both in neurites and presynaptic vesicles of neuronal cells (supplementary Fig. S2).

\section{Locomotor activity changes induced upon $\alpha$-synuclein expression}

Previous work clearly established that GFP overexpression in the NAcc has no significant effect on locomotor activity, compared with naïve animals (Bahi et al., 2004a,b). For this reason, Lenti-GFPtreated animals have been used as a control in the behavioural test (Fig. 6). Animals infected with Lenti-GFP displayed a significant induction of locomotor activity after cocaine administration, with a peak at $\sim 4100 \mathrm{~mm} / \mathrm{min}$ at $30 \mathrm{~min}$ (i.e. $10 \mathrm{~min}$ after drug administration; Fig. 6A; upper row, right panel, 'Session A (no 


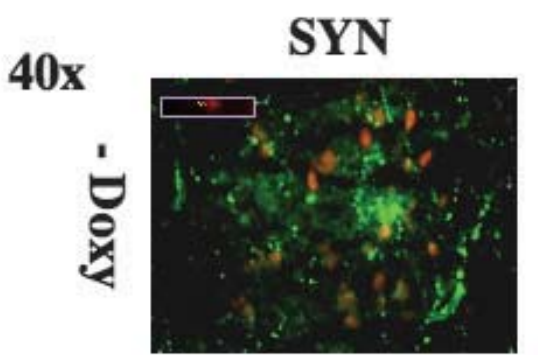

SYN+ SIL
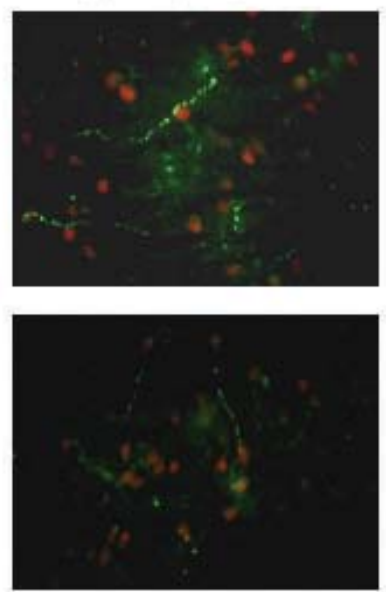

SIL
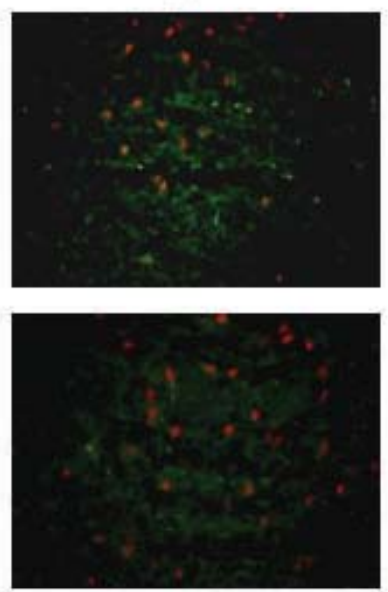

\section{GFP}
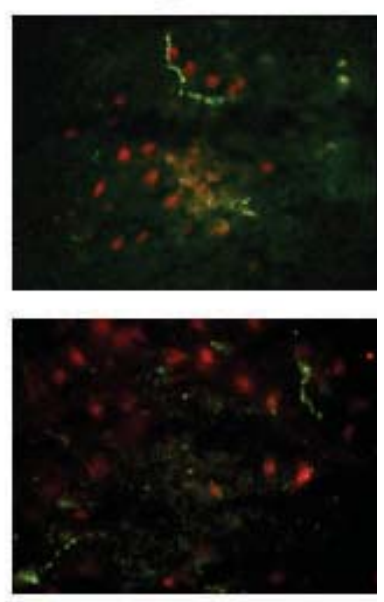

B
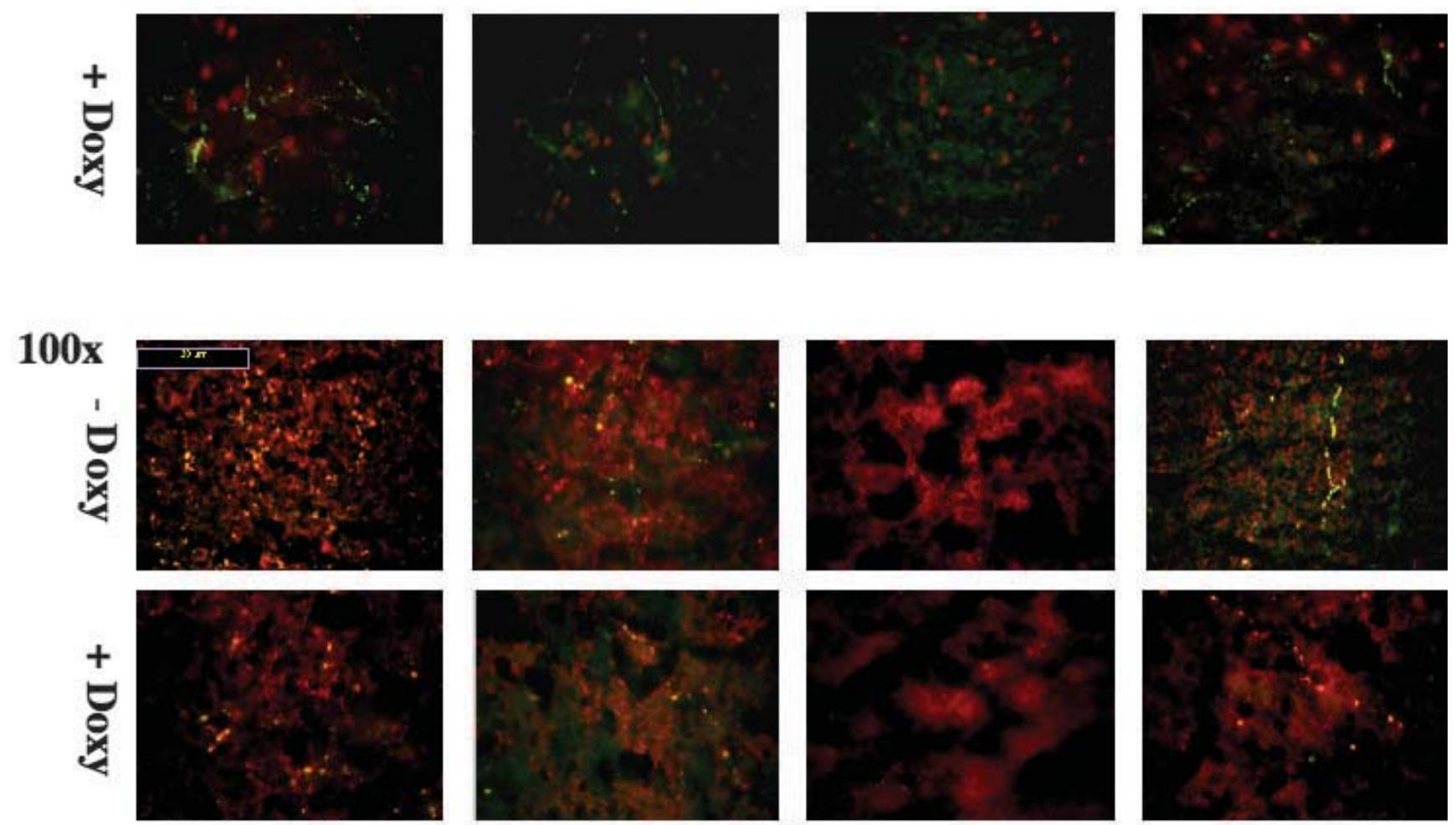

SYN

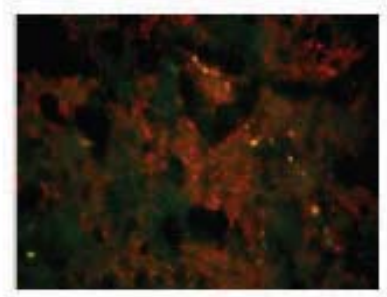

SYN+ SIL

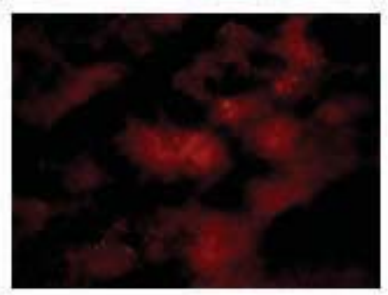

SIL

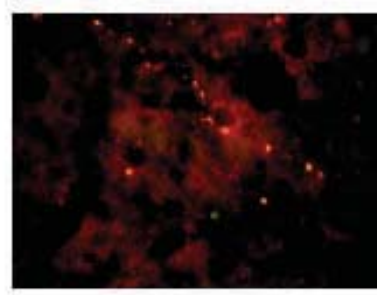

GFP

FIG. 5. Immunohistochemistry of $\alpha$-synuclein expression in the NAcc. Immunohistochemistry was performed after in vivo delivery of either: (a) Lenti- $\alpha$ Syn alone $(2 \mu \mathrm{L})$; (b) Lenti- $\alpha$ Syn $(2 \mu \mathrm{L})$ combined with Lenti- $\alpha$ Syn-siRNAs $(2 \mu \mathrm{L})$; (c) Lenti- $\alpha$ Syn-siRNAs $(2 \mu \mathrm{L})$; or (d) Lenti-green fluorescent protein $(\mathrm{GFP}$; $2 \mu \mathrm{L})$. Lentiviruses were injected into the NAcc according to the coordinates described in the Materials and methods. Animals used for behavioural analysis were fed either $5 \%$ sucrose or $5 \%$ sucrose $/ 0.02 \%$ doxycycline (see text for details). Animals were killed at the end of behavioural analyses; brains were dissected out and processed for immunohistochemistry (see Materials and methods). Upper panels: expression of $\alpha$-synuclein from animals fed 5\% sucrose; lower panels: expression of $\alpha$-synuclein from animals under doxycycline treatment. (A) Sections were double-labelled using antibodies against $\alpha$-synuclein (green) and NeuN (red), and visualized by fluorescence microscopy at $40 \times$ magnitude. Lentiviral overexpression of $\alpha$-synuclein shows an increase of $\alpha$-synuclein (green) that is not co-localized with the nuclei neurons labelling (red), but seems more likely expressed in neurites. (B) Sections were double-labelled using antibodies against $\alpha$-synuclein (green) and synaptophysin (red), and visualized by fluorescence microscopy at $100 \times$ magnitude. Yellow colour shows a large proportion of synaptic terminals co-expressing $\alpha$-synuclein and synaptophysin.

dox)'). During Session B (i.e. animals fed doxycycline), the distance travelled after cocaine injection was not significantly altered, with a peak at $\sim 5000 \mathrm{~mm} / \mathrm{min}$ at $30 \mathrm{~min}$ (Fig. 6A; middle row, right panel, 'Session B (dox)'). Upon doxycycline removal (Session C), enabling for GFP re-expression, the locomotor activity was similar to the other sessions, with a peak at $\sim 4200 \mathrm{~mm} / \mathrm{min}$ at $30 \mathrm{~min}$ (Fig. 6A; lower row, right panel, 'Session C (no dox)').

Animals infected with Lenti- $\alpha$ Syn displayed a significant increase $(68 \%)$ in locomotor activity after cocaine administration, compared with Lenti-GFP-treated animals, with a peak at $\sim 6800 \mathrm{~mm} / \mathrm{min}$ observed $10 \mathrm{~min}$ after drug administration (Fig. 6A; upper row, left panel, 'Session A (no dox)', $\left.F_{3,224}=236.1, P<0.001\right)$. After 5 days the same animals were fed doxycycline in the drinking water, inducing a downregulation of exogenous lentivirus-expressed $\alpha$-synuclein in the NAcc. Two days after the doxycycline switch, behaviour upon chronic cocaine administration was further monitored for five consecutive days (Session B). The distance travelled after cocaine injection displayed a peak at $\sim 5100 \mathrm{~mm} / \mathrm{min}$ at $30 \mathrm{~min}$ (Fig. 6A; middle row, left panel, 'Session B (dox)'), i.e. almost identical to levels observed with Lenti-GFP-treated animals $\left(P>0.05, F_{3224}=688.36\right)$. After 5 days monitoring under this regimen, doxycycline was removed (Session C), enabling re-expression of lentivirus-mediated $\alpha$-synuclein in the NAcc). Behaviour, measured 2 days later for five consecutive days under these conditions, expressed a peak of locomotor activity at 


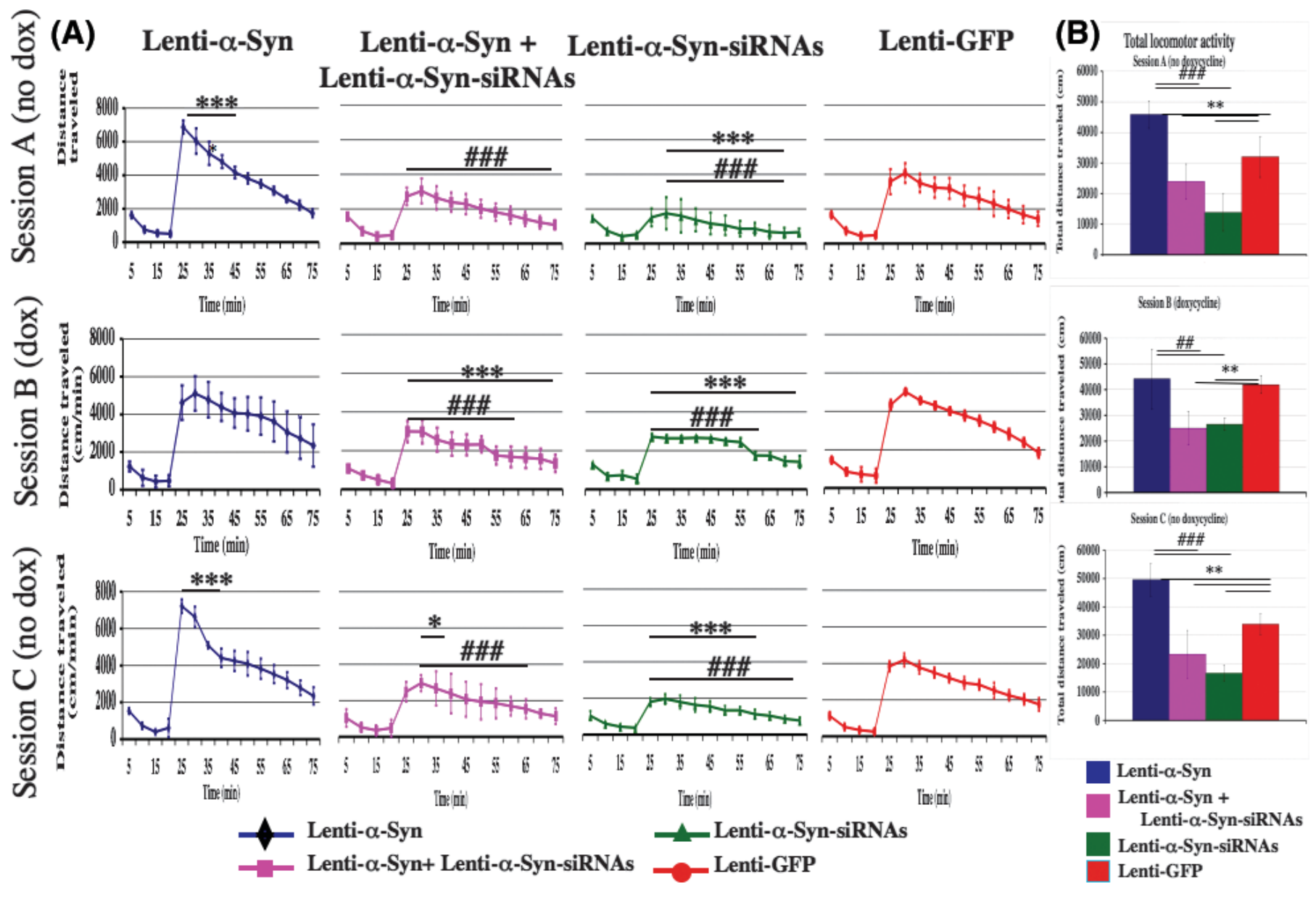

FIG. 6. (A and B) In vivo effects of $\alpha$-synuclein overexpression or silencing in the NAcc on cocaine-induced locomotor activity. Values represent means \pm SEM of 5 days $(n=8)$. One week after surgery, chronic cocaine delivery was started and locomotor activity was monitored. At each daily session, animals received saline injections before the habituation period $(15 \mathrm{~min}$ ) followed by cocaine delivery (i.p. $15 \mathrm{mg} / \mathrm{kg}$ ), and the locomotor activity was monitored immediately after drug injection. Overexpression of $\alpha$-synuclein in the NAcc induced a significant increase on cocaine-induced locomotor activity that could be abolished by doxycycline treatment. Silencing of $\alpha$-synuclein lead to a decrease of cocaine-induced locomotor activity. $* P<0.05, * * P<0.01$ and $* * * P<0.001$, vs data from Lenti-green fluorescent protein (GFP)-infected rats; ${ }^{\# \#} P<0.01$ and ${ }^{\# \# \#} P<0.001$ vs data from Lenti-asyn-injected rats, two-way ANOvA, Bonferroni post hoc tests.

$\sim 7300 \mathrm{~mm} / \mathrm{min}$ at $30 \mathrm{~min}$ (Fig. 6; lower row, left panel, 'Session C (no dox)', $F_{3,224}=544.33, P<0.001$ ). The difference between peaks in Sessions $\mathrm{A}$ and $\mathrm{C}$ was not significant $(P>0.2)$.

Another group, co-injected Lenti- $\alpha$ Syn and Lenti- $\alpha$ Syn-siRNAs, was submitted to the same series of regimen and cocaine treatment. In Session A, locomotor activity was significantly lower than in the previous group under the same conditions, with a peak at $\sim 3100 \mathrm{~mm} / \mathrm{min}$ at $30 \mathrm{~min}$ (Fig. 6A; upper row, central panel, 'Session A (no dox)', $P<0.001$ as compared with $\alpha$-synucleintreated group, $F_{3,224}=236.12$ ). In Session $\mathrm{B}$, locomotor activity slightly decreased, with a peak of $\sim 2900 \mathrm{~mm} / \mathrm{min}$ at $30 \mathrm{~min}$ (Fig. 6A; middle row, central panel, 'Session B (dox)'; $P<0.001$ as compared with $\alpha$-synuclein-treated group; $\left.F_{3,224}=688.36\right)$. Under these conditions, downregulation of exogenous, lentivirus-mediated $\alpha$-synuclein expression is achieved, together with knockdown of endogenous (cocaine-induced) expression. The observed residual behavioural activity is about $30 \%$ lower than in corresponding GFPtreated animals, as in the absence of $\alpha$-synuclein-specific siRNAs, synuclein would be strongly induced by cocaine under these conditions. In Session $\mathrm{C}$, when doxycycline has been removed from water on the same animals, enabling full expression of the ectopic $\alpha$ synuclein in the NAcc, the locomotor activity drops to the basal level, reaching levels comparable to the first session ( $\sim 3000 \mathrm{~mm} / \mathrm{min} 15 \mathrm{~min}$ after cocaine delivery; Fig. 6A; lower row, central panel, 'Session C (no dox)', $P<0.001$ as compared with $\alpha$-synuclein-treated group, $\left.F_{3,224}=544.33\right)$.

The last group of animals, infected only with Lenti- $\alpha$ Syn-siRNAs to assess effects of endogenous $\alpha$-synuclein, displayed very low locomotor activity $\sim 1700 \mathrm{~mm} / \mathrm{min}$ at $30 \mathrm{~min}$ in the absence of doxycycline (Fig. 6A; upper row, right panel, 'Session A (no dox)', $P<0.001, F_{3,224}=236.12$ as compared with $\alpha$-synuclein-treated group). In Session B, i.e. when switched to the doxycycline regimen, no significant change was observed, with a peak of $\sim 2600 \mathrm{~mm} / \mathrm{min}$ at $30 \mathrm{~min}$ (Fig. 6A; middle row, right panel 'Session B (dox)', $P<0.001$ as compared with $\alpha$-synuclein-treated group, $\left.F_{3,224}=688.36\right)$. Upon doxycycline removal, 5 days later, locomotor activity peaked at $\sim 2000 \mathrm{~mm} / \mathrm{min}$ (Fig. 6A; lower row, right panel, 'Session C (no dox)', $P<0.001$ as compared with $\alpha$ synuclein-treated group, $F_{3,224}=544.33$ ). The observed difference between these three sessions within this group of animals was not significant $(P>0.2)$. These observed behavioural effects were highly correlated with changes of $\alpha$-synuclein, as verified at protein levels by means of Western blot analysis (Fig. 4) and immunohistochemistry (Fig. 5). 
Drug-induced behavioural sensitization was observed during Session A for all groups, over the five initial days (Fig. 7). Sensitization is highest in the Lenti-GFP-treated animals, which display a $63 \%$ increase in locomotor activity over this session, vs about $15 \%$ increase in $\alpha$-synuclein-overexpressing animals $\left(P<0.001, F_{2,48}=10.52\right)$. Silencing $\alpha$-synuclein raises this effect, to values close to GFP-treated animals. During subsequent Sessions B and C, further sensitization could not be observed significantly $\left(P>0.05, F_{6,48}=5.24\right)$.

\section{Changes in $S A$ upon $\alpha$-synuclein expression}

Three groups of animals $(n=8)$ were used to test the effects of $\alpha$-synuclein expression in the NAcc on the cocaine SA paradigm (Fig. 7). One group was injected with the doxycycline regulatable Lenti-aSyn, a second group was co-injected with Lenti- $\alpha$ Syn and Lenti- $\alpha$ Syn-siRNAs, and a third group was injected with the doxycycline regulatable Lenti-GFP and served as a control group. Animals were trained for SA, then operated, as described in the Materials and methods. Data are presented in Fig. 8.

GFP-injected animals demonstrated a strong SA behaviour under a FR5 schedule of reinforcement with a mean of 15.5 infusions per session. After 5 days, the same animals were fed with doxycycline in the drinking water. During two consecutives days, animals could SA cocaine, but behaviour was not measured in order to achieve a full doxycycline switch of $\alpha$-synuclein expression before measurements. Thereafter, SA was further monitored for five consecutive days under doxycycline (Session B). Under these conditions the number of infusions was unchanged, with a mean at 15.2 per session.

The second group, injected with Lenti- $\alpha$ Syn and overexpressing of $\alpha$-synuclein in the NAcc, displayed a strong increase in SA of cocaine during Session A, with a mean of 30 infusions per session, i.e. a 1.9fold increase over the control GFP group $\left(F_{2,180}=745.64\right.$, $P<0.001)$. After 5 days, animals were fed doxycycline (Session B), suppressing $\alpha$-synuclein overexpression, and SA was measured 2 days later for five consecutive days. Under these conditions, the number of cocaine self-infusions dropped to 18.2 per session $(P>0.05)$.

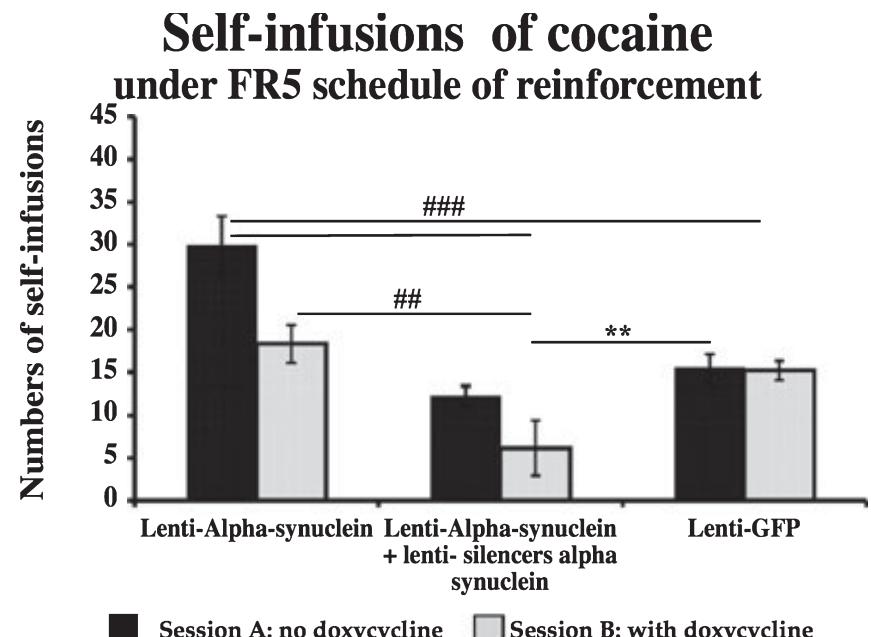

FIG. 8. Effects of $\alpha$-synuclein on cocaine SA under fixed ratio (FR) 5 schedule of reinforcement. Each histogram represents the means of dose-response for five consecutive days $(n=8)$. SA was performed for five consecutive days in the presence of doxycycline in the drinking water (Session A); then doxycycline was removed (Session B). Overexpression of $\alpha$-synuclein in the NAcc results in a significant increase in the number of cocaine SA. This change could be abolished by doxycycline treatment. ${ }^{*} P P<0.01$ vs data from LentiGFP-infected rats; ${ }^{\#} P<0.01$ and ${ }^{\# \#} P<0.001$ vs data from $\alpha$-synucleininjected rats, two-way ANOVA, Bonferroni post hoc tests. Results show an increase in numbers of cocaine self-infusions in animals injected with Lenti$\alpha$-Syn as compared with the Lenti-green fluorescent protein (GFP)-injected

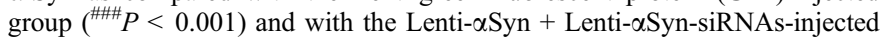
group. Therefore, after doxycycline treatment, animals injected with Lenti$\alpha$ Syn still display a significant increase in numbers of cocaine self-infusions as compared with Lenti- $\alpha$ Syn + Lenti- $\alpha$ Syn-siRNAs rats $\left({ }^{\#} P<0.01\right)$.

The third group of animals - co-injected with Lenti- $\alpha$-Syn and Lenti- $\alpha$ Syn-siRNAs - displayed a mean of 12.2 infusions per session in Session A, not significantly different from the control group $(P>0.05)$. Doxycycline treatment switches off Lenti- $\alpha$ Syn but not

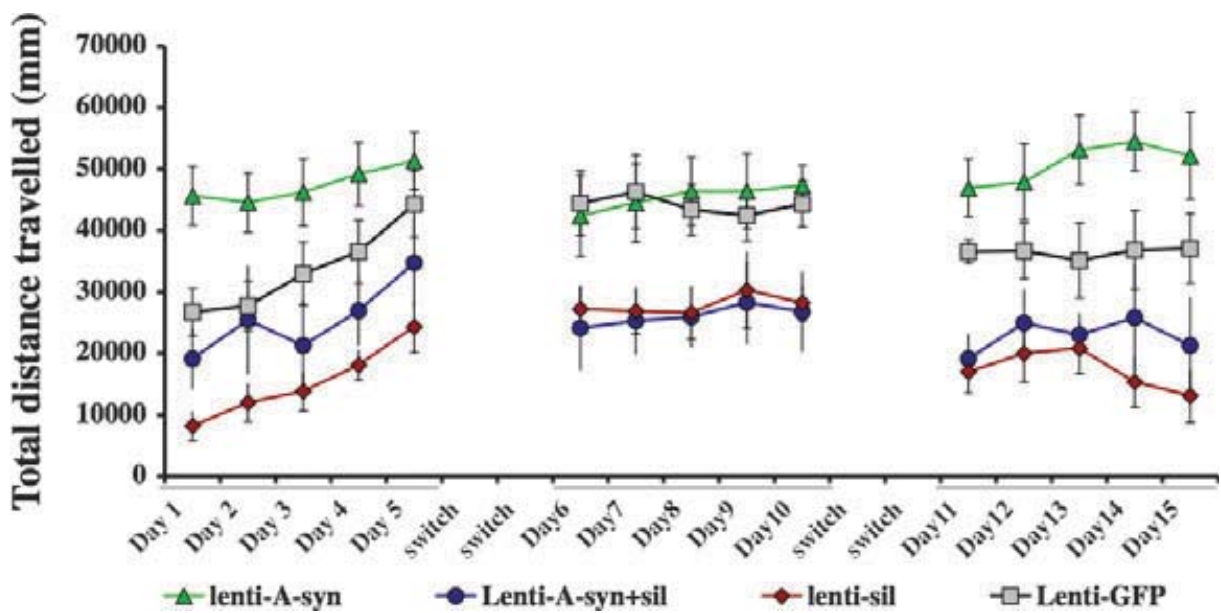

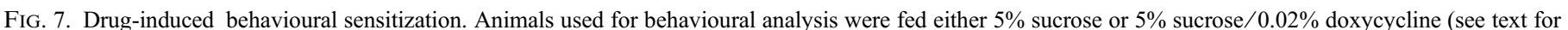

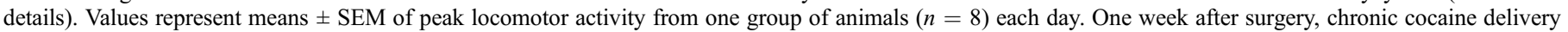

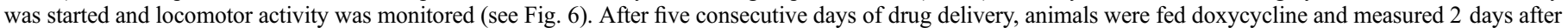

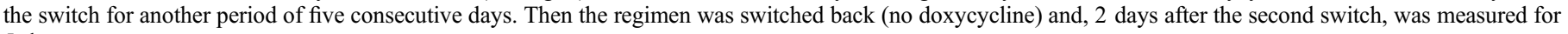
5 days. 
Lenti- $\alpha$ Syn-siRNAs, resulting both in a suppression of lentivirusmediated $\alpha$-synuclein overexpression as well as in silencing endogenous $\alpha$-synuclein expression. Under these conditions (Session B), animals displayed a very high decrease in cocaine SA, with a mean of 6.2 infusions per session. This represents a $40.8 \%\left(F_{2,180}=745.64\right.$, $P<0.01)$ and $34.1 \%\left(F_{2,180}=745.64, P<0.01\right)$ decrease in the number of cocaine self-infusion, compared with the GFP control group and the $\alpha$-synuclein-injected group, respectively, under the same conditions.

\section{Discussion}

In the present study we aimed at establishing a causal relationship between alterations in $\alpha$-synuclein levels and cocaine-induced behaviours. To this end, we have developed inducible lentiviral tools that very efficiently enable to locally alter $\alpha$-synuclein levels, and studied the consequences of varying $\alpha$-synuclein levels on cocaine-induced locomotion and SA. In previous studies we showed that cocaine administration induces a strong increase of $\alpha$ - and $\gamma$-synucleins in the NAcc (Brenz-Verca et al., 2003). This was corroborated in the present study: upon cocaine administration, $\alpha$-synuclein mRNA in GFP-treated animals is induced 3.1 -fold in the NAcc, compared with naïve, saline control animals. There is correlative evidence in humans that cocaine abusers overexpress $\alpha$-synuclein in dopaminergic neurons, mainly in the VTA and substantia nigra (Mash et al., 2003).

In this study we present evidence that an increase in $\alpha$-synuclein expression strongly correlates with behavioural changes observed under different drug administration paradigms. Our data clearly show a differential effect of overexpression and siRNA conditions with locomotion correlating with expression level. Local overexpression of $\alpha$-synuclein in the NAcc rapidly induces increased locomotor response to cocaine and increased SA of the drug, both effects that can be fully reversed in the presence of doxycycline. Furthermore, selective knockdown of $\alpha$-synuclein in the NAcc also strongly affects both locomotor activity and SA. Behavioural effects strongly correlate mRNA and protein expression of $\alpha$-synuclein in this brain area. This suggests that $\alpha$-synuclein expression in the NAcc plays an important role in cocaine-mediated behaviour. Behavioural changes have been compared with GFP-treated animals, as previous studies established that GFP does not affect behaviour in the paradigms under investigation (Bahi et al., 2004a,b). In addition, saline-treated animals were used as control, showing that cocaine indeed has some effects on $\alpha$-synuclein mRNA levels in the NAcc. The increased SA of cocaine suggests that enhanced expression of $\alpha$-synuclein makes the animals less sensitive to cocaine. The reinforcing properties of cocaine appear to have decreased, as suggested by the increased number of self-infusion, thus $\alpha$-synuclein overexpression may induce reduced cocaine reinforcement. The animals are compensating for the decreased effect by taking more drug. Therefore, increased $\alpha$-synuclein expression in the NAcc may result in enhanced locomotion induced by cocaine, but decreased reinforcing properties of the drug. On the other hand, our studies have so far been limited to single dose injection, and no dose-effect responses have been performed in the present study. Thus, it is also possible that $\alpha$-synuclein expression in the NAcc induces a rightward shift in the dose-effect curve. Shifts in dose-injection curves may reflect reward allostasis, not sensitization (Ahmed \& Koob, 2004), and escalated drug intake may often be suggestive of a negative reinforcement due to allostatic decrease in reward function (Ahmed \& Koob, 1999, 2005). Further studies at different doses may clarify this.
Interestingly, changes in $\alpha$-synuclein expression result in apparent cocaine-induced sensitization in the first sessions (Session A), but no more in Sessions B and C. However, the absence of sensitization in synuclein knockdown animals could be interpreted as the results of a ceiling effect. The level of cocaine-induced locomotion may then be so high already on the first exposure that there are no further possibilities for a further increase. As a matter of fact, cocaine-induced sensitization cannot be reversed on the very same animal fed doxycycline, then upon doxycycline removal. On the other hand, behavioural sensitization can arise from neuroadaptations in multiple brain nuclei (Vanderschuren \& Kalivas, 2000), and our data could rather reflect the differential involvement of the accumbens vs other brain regions in the expression or induction of cocaine sensitization. Indeed, cortical and allocortical brain regions such as the prefrontal cortex appear to be more critical for cocaine sensitization.

It has been established that cocaine abuse elevates $\alpha$-synuclein and DAT levels in the human striatum (Qin et al., 2005). In addition, $\alpha$-synuclein interactions with the DAT mediate the reuptake of DA released into the synaptic cleft by DA-producing neurons (Perez \& Hastings, 2004; Vekrellis et al., 2004; Wersinger \& Sidhu, 2005). This interaction regulates dopaminergic content, neurotransmission and synaptic strength at dopaminergic terminals (Zhou et al., 2002). Studies in $\alpha$-synuclein knockout mice revealed that it might inhibit refilling and reduce the storage capacity of presynaptic DA-containing vesicles, thus serving as a negative regulator of dopaminergic neurotransmission (Abeliovich et al., 2000; Yavich et al., 2004). $\alpha$-Synuclein exerts modulatory effects on DAT function, as well as on tyrosine hydroxylase activity, the rate-limiting enzyme in DA biosynthesis (Clayton \& George, 1999; Perez et al., 2002), and on vesicular storage of DA (Ueda et al., 1993; Akopian \& Wood, 1995). This would imply that a primary normative function of $\alpha$-synuclein in DA-producing neurons might be the regulation and maintenance of DA homeostasis (Neystat et al., 1999; Lotharius et al., 2002). The high concentration of synucleins in presynaptic terminals suggested an essential role for synucleins in synapse formation, neurotransmitter release or synaptic plasticity (Clayton \& George, 1998). As a matter of fact, our data may strongly support this view, as changes in its expression in the NAcc strongly affects reward, a process essentially related to DA release in this brain area. In our study, viral injection was performed into the NAcc. Lentiviruses being replication incompetent and self-inactivating, they will not spread away from the injected area.

Because of its high levels and its role in dopaminergic pathways, it has been suggested that $\alpha$-synuclein could be potentially involved in the effects exerted by psychostimulants on the dopaminergic reward pathway. $\alpha$-Synuclein mRNA regulation by chronic morphine administration in the mouse amygdala, a target region of dopaminergic projection, plays an essential role in reinstatement of opiate-reinforced behaviours (Sutcliffe et al., 2000; Fuchs \& See, 2002; Shalev et al., 2002). On the other hand, mice withdrawn from chronic morphine treatment display downregulation of $\alpha$-synuclein mRNA in the NAcc and related brain areas, e.g. the basolateral amygdala, the dorsal striatum and the VTA (Ziolkowska et al., 2005), in agreement with the observation reported in our present study for chronic cocaine. The changes were the most pronounced after longer periods of withdrawal, and were significantly increased in the striatum/accumbens for as long as 2 weeks after treatment cessation (Ziolkowska et al., 2005).

Synucleins are not essential for basic synaptic functions (e.g. neurotransmitter release, synaptic vesicle numbers and pools, and synaptic plasticity), but are redundantly required for maintaining normal DA levels in the nigrostriatal system (Chandra et al., 2004). No major phenotype was observed in $\alpha$-synuclein knockout mice (Abeliovich et al., 2000). A confounding problem in studying 
$\alpha$-synuclein is the presence of $\beta$ - and $\gamma$-synucleins, highly homologous isoforms (Ueda et al., 1993; Akopian \& Wood, 1995; George et al., 1995; Ji et al., 1997). The $\alpha$ - and $\beta$-synucleins are widely co-localized in presynaptic nerve terminals throughout the brain, but absent from peripheral tissues (Maroteaux et al., 1988). In contrast, $\gamma$-synuclein is abundant in specialized neurons, such as dorsal root ganglia (Akopian \& Wood, 1995; Murphy et al., 2000), and in non-neuronal tissues or certain tumour cells (Ji et al., 1997; Buchman et al., 1998; Surguchov et al., 1999). The high degree of co-expression of $\alpha$ - and $\beta$-synuclein indicates the potential for functional redundancy, which may have obscured an essential role of $\alpha$-synuclein in $\alpha$-synuclein knockout mice. The tools we have developed circumvent these difficulties, and enable for very local gene transfer and very local changes of gene expression. Because $\alpha$-synuclein is described as a widely presynaptic protein, the cocaine-mediated changes in mRNA and protein levels that we report in this study are likely to take place in the same populations of projection neurons. Axonal localization of $\alpha$-synuclein was confirmed by immunofluorescent labelling. Other studies, however, described further increased mRNA expression in response to, e.g. morphine in distinct populations as well, whose somata are in different brain areas (Ziolkowska et al., 2005).

From our studies, a role for $\alpha$-synuclein in addiction to cocaine may clearly be postulated. However, addiction refers to a specific pattern of compulsive drug-seeking and drug-taking behaviour, one that predominates over most other activities in life (Robinson, 2004; Vanderschuren \& Everitt, 2004). Deroche-Gamonet clearly identified addiction as the result from the interaction of two variables (Deroche-Gamonet et al., 2004): (i) the degree of exposure to drugs (because addiction-like behaviour appears only after extended access to cocaine); and (ii) the degree of vulnerability in the exposed individual (because, despite a similar drug intake in all subjects, addiction-like behaviour appears only in a few). It is the interaction between a long exposure to drug and a vulnerable phenotype, not one or the other factor in itself, that seems to determine the development of addiction. The vulnerable phenotype greatly depends on local drug-mediated expression changes of a very large array of genes, as addiction is largely a multigenetic brain disorder. A sound characterization of the role of the different genes regulated upon addiction, as exemplified with the highly specific tools developed in this study for $\alpha$-synuclein, is therefore essential for understanding the molecular mechanisms involved in this process. Our results demonstrate that $\alpha$-synuclein is able to modulate cocaine-induced behavioural effects. This suggests that targeting $\alpha$-synuclein function could provide new therapeutic strategies to treat cocaine abuse for which there is no available treatment.

\section{Supplementary material}

The following supplementary material may be found on http://www.blackwell-synergy.com

Fig. S1. Immunohistochemistry of $\alpha$-synuclein and NeuN expression in the Nacc.

Fig. S2. Immunohistochemistry of $\alpha$-synuclein expression in the NAcc.

\section{Acknowledgements}

This study was supported by Swiss National Foundation grants 3100-059350 and 3100AO-100686 (J.L.D.). The authors are very grateful to Mrs V. DerocheGamonet (Institute for Neurosciences, Inserm538, Bordeaux) for scientific support and for critical comments and reading of the manuscript, and to Dr A. Bahi and Mrs C. Deforel-Poncet for skilful assistance.

\section{Abbreviations}

DA, dopamine; DAT, dopamine transporter; FR, fixed ratio; GAPDH, glyceralaldehyde-3-phosphate-dehydrogenase; GFP, green fluorescent protein; HEK, human embryonic kidney; NAcc, nucleus accumbens; PBS, phosphatebuffered saline; PCR, polymerase chain reaction; SA, self-administration; TBST, Tris-buffered Saline Tween-20; VTA, ventral tegmental area.

\section{References}

Abeliovich, A., Schmitz, Y., Farinas, I., Choi-Lundberg, D., Ho, W.H., Castillo, P.E., Shinsky, N., Verdugo, J.M., Armanini, M. \& Ryan, A. (2000) Mice lacking alpha-synuclein display functional deficits in the nigrostriatal dopamine system. Neuron, 25, 239-252.

Ahmed, S.H. \& Koob, G.F. (1999) Long-lasting increase in the set point for cocaine self-administration after escalation in rats. Psychopharmacology, 146, 303-312.

Ahmed, S.H. \& Koob, G.F. (2004) Vertical shifts in dose-injection curves reflect reward allostasis, not sensitization. Psychopharmaclology, 171, 354355.

Ahmed, S.H. \& Koob, G.F. (2005) Transition to drug addiction: a negative reinforcement model based on an allostatic decrease in reward function. Psychopharmacology, 180, 473-476.

Akopian, A.N. \& Wood, J.N. (1995) Peripheral nervous system-specific genes identified by subtractive cDNA cloning. J. Biol. Chem., 270, 21264-21270.

Bahi, A., Boyer, F., Bussard, G. \& Dreyer, J.L. (2005a) Silencing dopamine D3receptor in the nucleus accumbens shell in vivo induces behavioral changes in cocaine-induced hyperlocomotion. Eur. J. Neurosci., 21, 3415-3426.

Bahi, A., Boyer, F., Gumy, C., Kafri, T. \& Dreyer, J.L. (2004a) In vivo gene delivery of urokinase-type plasminogen activator with regulatable lentivirus induces behavioral changes in chronic cocaine administration. Eur. J. Neurosci., 20, 3473-3488.

Bahi, A., Boyer, F., Kafri, T. \& Dreyer, J.L. (2004b) CD81-induced behavioral changes during chronic cocaine administration: in vivo gene delivery with regulatable lentivirus. Eur. J. Neurosci., 19, 1621-1633.

Bahi, A., Boyer, F., Kolira, M. \& Dreyer, J.L. (2005b) In vivo gene silencing of CD81 by lentiviral expression of small interference RNAs suppresses cocaine-induced behavior. J. Neurochem., 92, 1243-1255.

Bahi, A. \& Dreyer, J.L. (2004) Cocaine-induced expression changes of axon guidance molecules in the adult rat brain. Mol. Cell. Neurosci., 28, 275-291.

Baptista, M.J., O’Farrell, C., Daya, S., Ahmad, R., Miller, D.W., Hardy, J., Farrer, M.J. \& Cookson, M.R. (2003) Co-ordinate transcriptional regulation of dopamine synthesis genes by alpha-synuclein in human neuroblastoma cell lines. J. Neurochem., 85, 957-968.

Bennett, M.C., Bishop, J.F., Leng, Y., Chock, P.B., Chase, T.N. \& Mouradian, M.M. (1999) Degradation of alpha-synuclein by proteasome. J. Biol. Chem., 274, 33855-33858.

Bonsch, D., Greifenberg, V., Bayerlein, K., Biermann, T., Reulbach, U., Hillemacher, T., Kornhuber, J. \& Bleich, S. (2005) $\alpha$-Synuclein protein levels are increased in alcoholic patients and are linked to craving. Alcohol Clin. Exp. Res., 29, 763-768.

Bonsch, D., Reulbach, U., Bayerlein, K., Hillemacher, T., Kornhuber, J. \& Bleich, S. (2004) Elevated alpha synuclein mRNA levels are associated with craving in patients with alcoholism. Biol. Psychiatry., 56, 984-986.

Brenz-Verca, M.S., Bahi, A., Boyer, F., Wagner, G.C. \& Dreyer, J.L. (2003) Distribution of alpha- and gamma-synucleins in the adult rat brain and their modification by high-dose cocaine treatment. Eur. J. Neurosci., 18, 19231938.

Buchman, V.L., Hunter, H.J., Pinon, L.G., Thompson, J., Privalova, E.M., Ninkina, N.N. \& Davies, A.M. (1998). J. Neurosci., 18, 9335-9341.

Chandra, S., Fornai, F., Kwon, H.B., Yazdani, U., Atasoy, D., Liu, X., Hammer, R.E., Battaglia, G., German, D.C., Castillo, P.E. \& Südhof, T.C. (2004) Double-knockout mice for $\alpha$ - and $\beta$-synucleins: effect on synaptic functions. PNAS, 101, 14966-14971.

Clayton, D.F. \& George, J.M. (1998) The synucleins: a family of proteins involved in synaptic function, plasticity, neurodegeneration and disease. Trends Neurosci., 21, 249-254.

Clayton, D.F. \& George, J.M. (1999) Synucleins in synaptic plasticity and neurodegenerative disorders. J. Neurosci. Res., 58, 120-129.

Cooper, A.A., Gitler, A.D., Cashikar, A., Haynes, C.M., Hill, K.J., Bhullar, B., Liu, K., Xu, K., Strathearn, K.E., Liu, F., Cao, S., Caldwell, K.A., Caldwell, G.A., Marsischky, G., Kolodner, R.D., LaBaer, J., Rochet, J.C., Bonini, N.M. \& Lindquist, S. (2006) $\alpha$-Synuclein blocks ER-Golgi traffic and Rab1 rescues neuron loss in Parkinson's models. Science, 313, 324-328. 
Deroche-Gamonet, V., Belin, D. \& Piazza, P.V. (2004) Evidence for addictionlike behavior in the rat. Science, 305, 1014-1017.

Fornai, F., Lazzeri, G., diPoggio, A.B., Soldani, P., de Blasi, A., Nicoletti, F., Ruggieri, S. \& Paparelli, A. (2006) Convergent roles of $\alpha$-synuclein, DA metabolism, and the ubiquitin-proteasome system in nigrostriatal toxicity. Ann. NY Acad. Sci., 1074, 84-89.

Fuchs, R.A. \& See, R.E. (2002) Basolateral amygdala inactivation abolishes conditioned stimulus- and heroin-induced reinstatement of extinguished heroin-seeking behavior in rats. Psychopharmacology, 160, 425-433.

George, J.M. (2001) Protein family review: the synucleins. Genome Biol., 3, $3002.1-3002.6$

George, J.M., Jin, H., Woods, W.S. \& Clayton, D.F. (1995) Characterization of a novel protein regulated during the critical period for song learning in the zebra fish. Neuron, 15, 361-372.

Goedert, M. (2001) Alpha-synuclein and neurodegenerative diseases. Nat. Rev. Neurosci., 2, 492-501.

Ji, H., Liu, Y.E., Jia, T., Wang, M., Liu, J., Xiao, G., Joseph, B.K., Rosen, C. \& Shi, Y.E. (1997) Identification of a breast cancer-specific gene, BCSG1, by direct differential cDNA sequencing. Cancer Res., 57, 759-764.

Kobayashi, H., Ide, S., Hasegawa, J., Ujike, H., Sekine, Y., Ozaki, N., Inada, T., Harano, M., Komiyama, T., Yamada, M., Iyo, M., Shen, H.W., Ikeda, K. \& Sora, I. (2004) Study of association between $\alpha$-synuclein gene polymorphism and methamphetamine psychosis/dependence. Ann. N Y Acad. Sci., 1025, 325-334.

Kruger, R., Kuhn, W., Muller, T., Woitalla, D., Graeber, M., Kosel, S., Przuntek, H., Epplen, J.T., Schols, L. \& Riess, O. (1998) Ala30Pro mutation in the gene encoding alpha-synuclein in Parkinson's disease. Nat. Genet., 18, 106-108.

Lee, F.J., Liu, F., Pristupa, Z.B. \& Niznik, H.B. (2001) Direct binding and functional coupling of alpha-synuclein to the dopamine transporters accelerate dopamine-induced apoptosis. FASEB J., 15, 916-926.

Li, J.Y., Henning Jensen, P. \& Dahlstrom, A. (2002) Differential localization of alpha-, beta- and gamma-synucleins in the rat CNS. Neuroscience, 113, 463 478.

Liang, T., Spence, J., Liu, L., Strother, W.N., Chang, H.W., Ellison, J.A., Lumeng, L., Li, T.K., Foroud, T. \& Carr, L.G. (2003) alpha-Synuclein maps to a quantitative trait locus for alcohol preference and is differentially expressed in alcohol-preferring and - nonpreferring rats. Proc. Natl Acad. Sci. USA, 100, 4690-4695.

Lotharius, J., Barg, S., Wiekop, P., Lundberg, C., Raymon, H.K. \& Brundin, P. (2002) Effect of mutant alpha-synuclein on dopamine homeostasis in a new human mesencephalic cell line. J. Biol. Chem., 277, 38884-38894.

Lotharius, J. \& Brundin, P. (2002) Impaired dopamine storage resulting from $\alpha$-synuclein mutations may contribute to the pathogenesis of Parkinson's disease. Human Mol. Genet., 20, 2395-2407.

Maroteaux, L., Campanelli, J.T. \& Scheller, R.H. (1988) Synuclein: a neuronspecific protein localized to the nucleus and presynaptic nerve terminal. J. Neurosci., 8, 2804-2815.

Mash, D.C., Ouyang, Q., Pablo, J., Basile, M., Izenwasser, S., Lieberman, A. \& Perrin, R.J. (2003) Cocaine abusers have an overexpression of alphasynuclein in dopamine neurons. J. Neurosci., 23, 2564-2571.

Mash, D.C., Pablo, J., Ouyang, Q., Hearn, W.L. \& Izenwasser, S. (2002) Dopamine transport function is elevated in cocaine users. J. Neurochem., 81, 292-300.

Maucelli, G., Busceti, C.I., Pellegrini, A., Soldani, P., Lenti, P., Paparelli, A. \& Fornai, F. (2006) Overexpression of alpha-synuclein following metamphetamine. Ann. N Y Acad. Sci., 1074, 191-197.

Mosharov, E.V., Staal, R.G.W., Bove, J., Prou, D., Hananiya, A., Markov, D., Poulsen, N., Larsen, K.E., Candace, M.H., Moore, M.H., Troyer, M.D., Edwards, R.H., Przedborski, S. \& Sulzer, D. (2006) $\alpha$-Synuclein overexpression increases cytosolic catecholamine concentration. J. Neurosci., 26, 9304-9311.

Murphy, D.D., Rueter, S.M., Trojanowski, J.Q. \& Lee, V.M. (2000) Synucleins are developmentally expressed, and alpha-synuclein regulates the size of the presynaptic vesicular pool in primary hippocampal neurons. J. Neurosci., 20, 3214-3220.

Neystat, M., Lynch, T., Przedborski, S., Kholodilov, N., Rzhetskaya, M. \& Burke, R.E. (1999) Alpha-synuclein expression in substantia nigra and cortex in Parkinson's disease. Mov. Disord., 14, 417-422.

Paxinos, G. \& Watson, C. (1998) The Rat Brain in Stereotaxic Coordinates, 4th Edn. Academic Press, San Diego, USA.
Perez, R.G. \& Hastings, T.G. (2004) Could a loss of $\alpha$-synuclein function put dopaminergic neurons at risk? J. Neurochem., 89, 1318-1324.

Perez, R.G., Waymire, J.C., Lin, E., Liu, J.J., Guo, F. \& Zigmond, M.J. (2002) A role for $\alpha$-synuclein in the regulation of dopamine biosynthesis. J. Neurosci., 22, 3090-3099.

Polymeropoulos, M.H., Lavedan, C., Leroy, E., Ide, S.E., Dehejia, A., Dutra, A., Pike, B., Root, H., Rubenstein, J. \& Boyer, R. (1997) Mutation in the alpha-synuclein gene identified in families with Parkinson's disease. Science, 276, 2045-2047.

Qin, Y., Ouyang, Q., Pablo, J. \& Mash, D.C. (2005) Cocaine abuse elevates alpha-synuclein and dopamine transporter levels in the human striatum. Neuroreport, 16, 1489-1493.

Robinson, T.E. (2004) Addicted rats. Science, 305, 951-953.

Shalev, U., Grimm, J.W. \& Shaham, Y. (2002) Neurobiology of relapse to heroin and cocaine seeking: a review. Pharmacol. Rev., 54, 142.

Sidhu, A., Wersinger, C. \& Vernier, P. (2004a) alpha-Synuclein regulation of the dopaminergic transporter: a possible role in the pathogenesis of Parkinson's disease. FEBS Lett., 565, 1-5.

Sidhu, A., Wersinger, C. \& Vernier, P. (2004b) Does alpha-synuclein modulate dopaminergic synaptic content and tone at the synapse? FASEB J., 18, 637634.

Surguchov, A., Surgucheva, I., Solessio, E. \& Baehr, W. (1999) Synoretin - a new protein belonging to the synuclein family. Mol. Cell. Neurosci., 13, 95103.

Sutcliffe, J.G., Foye, P.E., Erlander, M.G., Hilbush, B.S., Bodzin, L.J., Durham, J.T. \& Hasel, K.W. (2000) TOGA: an automated parsing technology for analyzing expression of nearly all genes. Proc. Natl Acad. Sci. USA, 97, 1967-1981.

Ueda, K., Fukushima, H., Masliah, E., Xia, Y., Iwai, A., Yoshimoto, M., Otero, D.A., Kondo, J., Ihara, Y. \& Saitoh, T. (1993) Molecular cloning of cDNA encoding an unrecognized component of amyloid in Alzheimer disease. Proc. Natl Acad. Sci. USA, 90, 11282-11286.

Vanderschuren, L.J.M.L. \& Everitt, B.J. (2004) Drug seeking becomes compulsive after prolonged cocaine self-administration. Science, 305, 1017-1019.

Vanderschuren, L.J. \& Kalivas, P.W. (2000) Alterations in dopaminergic and glutamatergic transmission in the induction and expression of behavioral sensitization. Psychopharmacology, 151, 99-120.

Vekrellis, K., Rideout, H.J. \& Stefanis, L. (2004) Neurobiology of alphasynuclein. Mol. Neurobiol., 30, 1-22.

Weiss, F., Lorang, M.T., Bloom, F.E. \& Koob, G.F. (1993) Oral alcohol selfadministration stimulates dopamine release in the rat nucleus accumbens: genetic and motivational determinants. Pharmacol. Appl. Ther., 267, 250258.

Wersinger, C., Prou, D., Vernier, P. \& Sidhu, A. (2003) Modulation of dopamine transporter function by alpha-synuclein is altered by impairment of cell adhesion and by induction of oxidative stress. FASEB J., 17, 21512153.

Wersinger, C., Rusnak, M. \& Sidhu, A. (2006) Modulation of the trafficking of the human serotonin transporter by human alpha-synuclein. Eur. J. Neurosci., 24, 55-64.

Wersinger, C. \& Sidhu, A. (2003) Attenuation of dopamine transporter activity by alpha-synuclein. Neurosci. Lett., 340, 189-189.

Wersinger, C. \& Sidhu, A. (2005) Disruption of the interaction of alphasynuclein with microtubules enhances cell surface recruitment of the dopamine transporter. Biochemistry, 44, 13612-13624.

Yavich, L., Tanila, H., Saila, V. \& Jakala, P. (2004) Role of alpha-synuclein in presynaptic dopamine recruitment. J. Neurosci., 24, 11165-11170.

Yujing, Q., Qinje, O., Pablo, J. \& Mash, D.C. (2005) Cocaine abuse elevates alpha-synuclein and dopamine transporter levels in the human striatum. Neuroreport, 16, 1489-1493.

Zhou, W., Schaack, J., Zawada, W.M. \& Freed, C.R. (2002) Overexpression of human alpha-synuclein causes dopamine neuron death in primary human mesencephalic culture. Brain Res., 926, 42-50.

Ziolkowska, B., Gieryk, A., Bilecki, W., Wawrzczak-Bargiela, A., Wedzony, K., Chocyk, A., Danielson, P.E., Thomas, E.A., Hilbush, B.S., Sutcliffe, J.G. \& Przewlocki, R. (2005) Regulation of alpha-synuclein expression in limbic and motor brain regions of morphine-treated mice. J. Neurosci., 25, 49965003. 